\title{
Five new species of Meta Koch, 1836 (Araneae: Tetragnathidae) from Gaoligong Mountains, China
}

\author{
Luyu WANG ${ }^{1}$, Guchun ZHOU ${ }^{2}$, Muhammad IRFAN ${ }^{3}$, Sufang YANG ${ }^{4} \&$ Xianjin PENG ${ }^{5, *}$ \\ ${ }^{1,3,5}$ College of Life Science, Hunan Normal University, Changsha 410081, Hunan, China. \\ ${ }^{2}$ College of life Sciences, National Navel Orange Engineering Research Center, \\ Gannan Normal University, Ganzhou 341000, Jiangxi, China. \\ ${ }^{4}$ College of Chemistry and Chemical Engineering, Hunan Normal University, \\ Changsha, 410081, Hunan, China \\ *Corresponding author: xjpeng@126.com \\ ${ }^{1}$ Email: 564464670@qq.com \\ ${ }^{2}$ Email: zhguch_23@163.com \\ 32Email: irfanuos94@yahoo.com \\ ${ }^{4}$ Email: yangsu03-11@163.com \\ *urn:1sid:zoobank.org:author:87E11EB5-D918-4E67-841E-B291C651FE72 \\ ${ }^{1}$ urn:lsid:zoobank.org:author:2DDF543A-06AC-4A44-95BE-FD32C1F85336 \\ ${ }^{2}$ urn:lsid:zoobank.org:author:961EEB65-05F4-44F3-A3B4-693B62FAB48E \\ ${ }^{3}$ urn:lsid:zoobank.org:author:4EE226DB-D810-4907-A4B6-B04F4E4241AB \\ ${ }^{4}$ urn:1sid:zoobank.org:author:A3720D98-7B42-4C99-837C-264EBF3BC5E4
}

\begin{abstract}
Five new species of the genus Meta C.L. Koch, 1836 from the Gongligong Mountains,

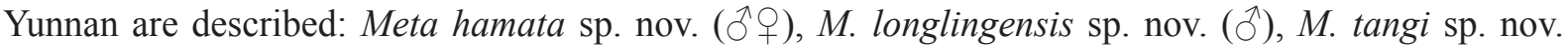

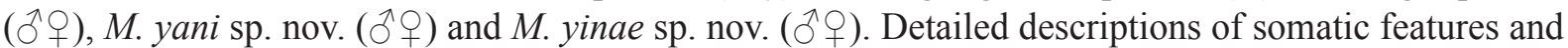
genitalic characters, photos of the body and genital organs, line drawings of the copulatory organs and distribution maps are provided.
\end{abstract}

Keywords. Description, illustration, taxonomy, Yunnan.

Wang L., Zhou G., Irfan M., Yang S. \& Peng X. 2020. Five new species of Meta Koch, 1836 (Araneae: Tetragnathidae) from Gaoligong Mountains, China. European Journal of Taxonomy 624: 1-25. https://doi.org/10.5852/ejt.2020.624

\section{Introduction}

The Gaoligong Mountains, located in western Yunnan, are a sub-range of the Hengduan Mountains with steep slopes, ranging in altitude from 645 to $4640 \mathrm{~m}$. They form a spectacular vertical natural landscape and have a wide variety of climates. They cover a total area of $111000 \mathrm{~km}^{2}$ that is considered a part of the Indo-Burmese biodiversity hotspot (Li et al. 2000; Myers et al. 2000). The diversity of spiders in the Gaoligong Mountains is very high. Seven new species of the genus Wolongia Zhu et al., 1997 and one new species of the genus Leucauge White, 1841 (Tetragnathidae) were reported by Wan \& Peng 
(2013a, 2013b); Wang et al. (2009, 2010) mentioned 71 species of Coelotinae (Agelenidae), 30 of which were new to science; Miller et al. (2009) described 36 new species of Symphytognathoidea. All these were added to the many endemic spider species that had already been reported in the last twenty years (Griswold et al. 1999; Yin et al. 2002, 2003a, 2003b, 2009; Xu et al. 2002).

The spider genus Meta C.L. Koch contains 24 species distributed worldwide (World Spider Catalog 2020), including five from China (Li \& Lin 2016): Meta mixta O. P.-Cambridge, 1885; M. nebulosa Schenkel, 1936; M. nigridorsalis Tanikawa, 1994; M. qianshanensis Zhu \& Zhu, 1983; and M. shenae Zhu et al., 2003. M. nebulosa has not been reported again since it was described from a juvenile holotype by Schenkel (1936). Spiders of the genus Meta live mainly in the gullies of shady woods or in shallow caves, where they make flat webs and situate themselves in the center of the web. While examining the specimens collected from Gaoligong Mountains, five new species of the genus Meta were recognized and are described here.

\section{Material and methods}

All specimens were preserved in 75\% ethanol and examined, illustrated, photographed and measured using a Leica M205C stereo microscope equipped with a drawing tube, a Leica MC170 camera and LAS software (Ver. 4.8). Male palps and female epigynes were examined and illustrated after being dissected. Female genitalia were cleared in $90 \%$ lactic acid. Eye sizes were measured as the maximum dorsal diameter. Leg measurements are shown as: total length (femur, patella and tibia, metatarsus, tarsus). All measurements are in millimeters. Specimens are deposited at the College of Life Sciences, Hunan Normal University, Changsha, China (HNU). Morphological terminology for descriptions and figures follows Álvarez-Padilla \& Hormiga (2011).

Abbreviations
$\mathrm{ALE}=$ anterior lateral eye
$\mathrm{AME}=$ anterior median eye
$\mathrm{CD}=$ copulatory duct
$\mathrm{CEP}=$ cymbial ectobasal process
$\mathrm{Co}=$ conductor
$\mathrm{Em}=$ embolus
$\mathrm{FD}=$ fertilization duct
$\mathrm{MEA}=$ metaine embolic apophysis
$\mathrm{MOA}=$ median ocular area
$\mathrm{Pa}=$ paracymbium
$\mathrm{PLE}=$ posterior lateral eye
$\mathrm{PME}=$ posterior median eye
$\mathrm{Sp}=$ spermathecae

\section{Results}

Class Arachnida Cuvier, 1812

Order Araneae Clerck, 1757

Family Tetragnathidae Menge, 1866

Genus Meta C.L. Koch, 1836

Meta hamata sp. nov.

urn:1sid:zoobank.org:act:B853796A-C1A3-4D15-8D95-2DC4A6D1E564

Figs $1 \mathrm{~A}-\mathrm{B}, 2-4$ 


\section{Differential diagnosis.}

Meta hamata sp. nov. can be distinguished from the other Chinese Meta species by the strong, tongueshaped metaine embolic apophysis, the wide conductor of the male palp (Figs 2, 4A-C) and the small spermathecae of the epigyne (Figs 3B, 4E). Meta hamata sp. nov. resembles M. yani sp. nov. (Figs 1012), but can be distinguished from the latter by: metaine embolic apophysis tongue-shaped in ventral view in M. hamata sp. nov. (Figs 2D, 4B), but with a bifurcated tip in M. yani sp. nov. (Figs 10D, 12B); embolus hook-shaped in M. hamata sp. nov. (Figs 2A, 4A), spine-shaped in M. yani sp. nov. (Figs 10A, 12A); conductor shorter than embolus in prolateral view in $M$. hamata sp. nov. (Figs 2A, 4A), longer than embolus in M. yani sp. nov. (Figs 10A, 12A); cymbial ectobasal process without the spine-like apophysis found in that of M. yani in ventral view (Figs 2D, 4B, 11D, 12B); posterior margin of the epigynal plate almost round in M. hamata sp. nov. (Figs 3B, 4E), centrally incised in M. yani sp. nov. (Figs 11B, 12E).

\section{Etymology}

The specific name comes from the Latin adjective 'hamatus', meaning 'hook-like', referring to the shape of the embolus in the male palp.

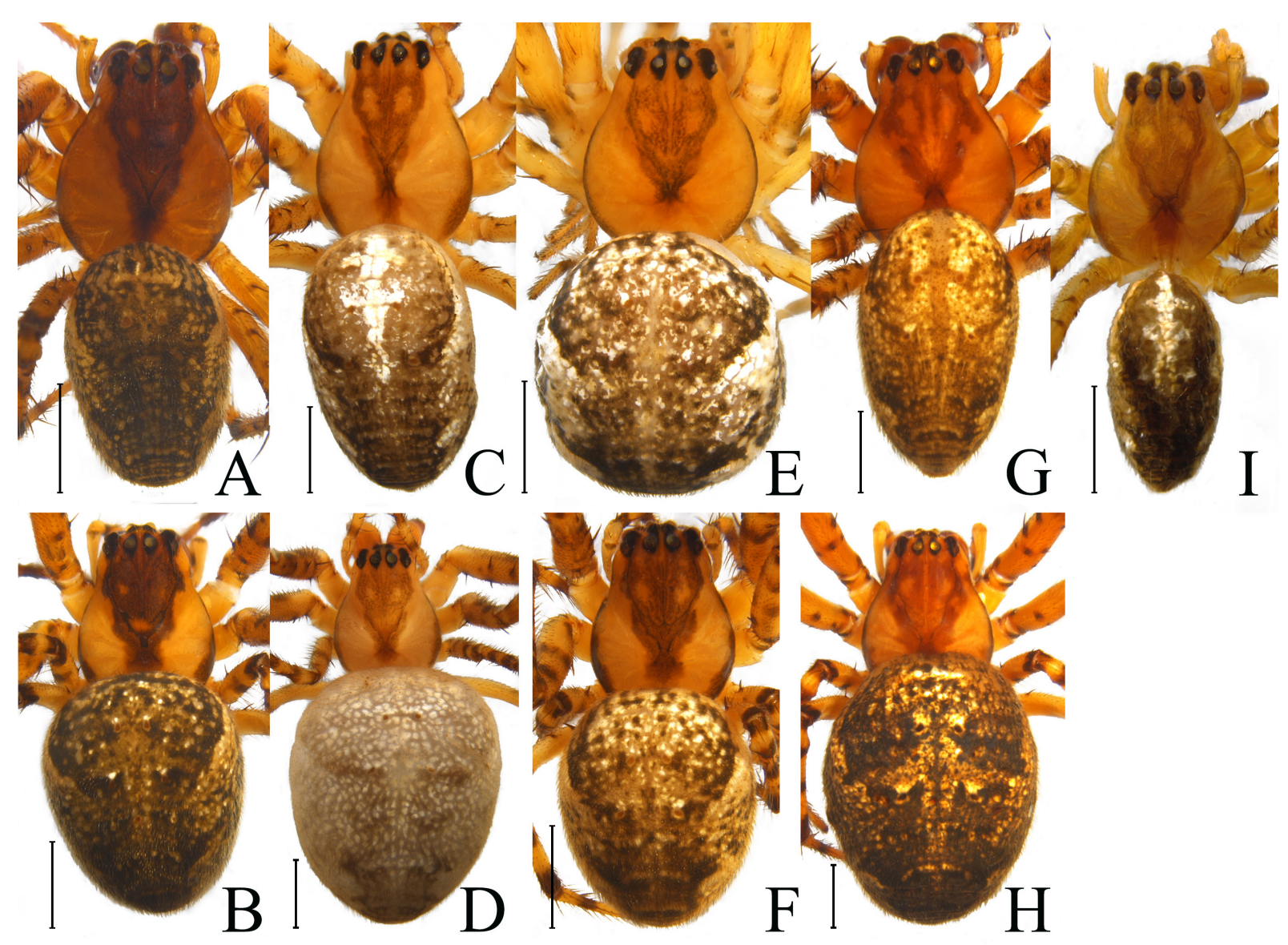

Fig. 1. Meta hamata sp. nov. (A-B), Meta longlingensis sp. nov. (I), Meta tangi sp. nov. (C-D), Meta yani sp. nov. (E-F), Meta yinae sp. nov. (G-H). A, C, E, G, I. Male holotype habitus, dorsal view. B, D, F, H. Female paratype habitus, dorsal view. Scale bars: $1 \mathrm{~mm}$. 
Type material.

\section{Holotype}

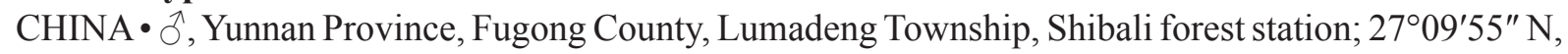
98 46'44" E; alt. 2525 m; 1-7 May 2004; C. Griswold and D.H. Kavanaugh leg.; HNU-CGY25.

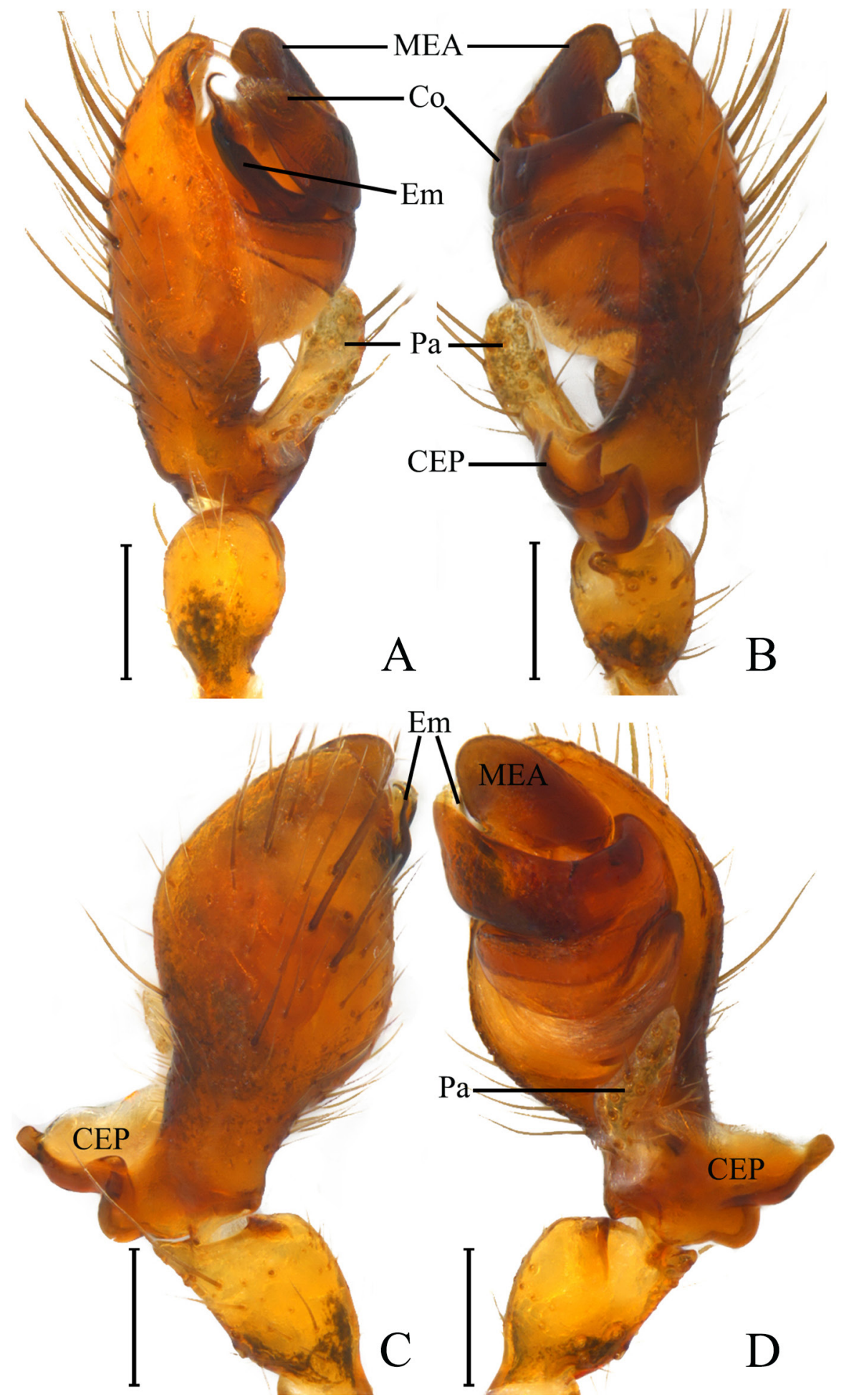

Fig. 2. Meta hamata sp. nov. Left palp, $\widehat{\jmath}$, holotype (HNU-CGY25): A. Prolateral view. B. Retrolateral view. C. Dorsal view. D. Ventral view. Scale bars: A-D $=0.2 \mathrm{~mm}$. 
Paratypes $(16 \hat{\delta} \hat{o}$ and $26 q q)$

CHINA - Yunnan Province - Fugong County • 6 त $\partial^{\lambda}, 6$ 우; same collection data as for holotype;

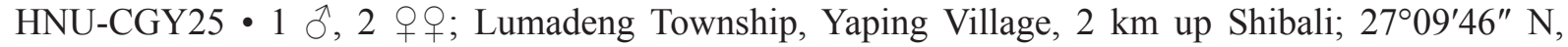
98 47'24" E; alt. 2730 m; 1 May 2004; G.X. Peng leg.; HNU-20040501-2 • 1 đ̃; 2 km down Shibali;

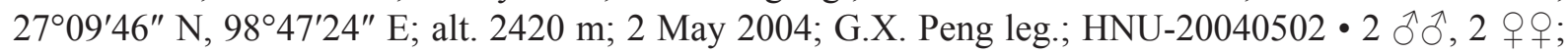

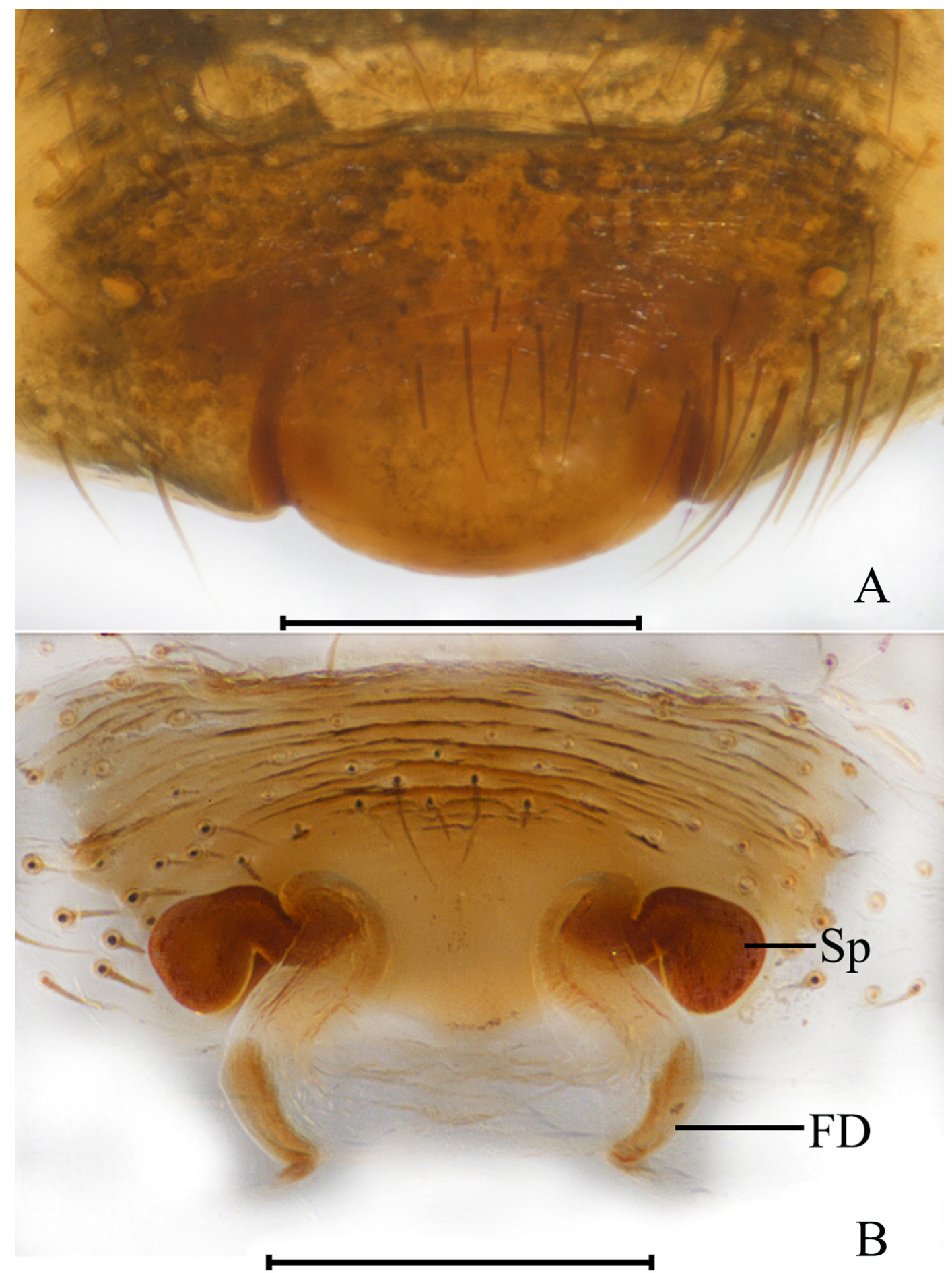

Fig. 3. Meta hamata sp. nov., paratype $q$ (HNU-CGY25). A. Epigyne, ventral view. B. Vulva, front view. Scale bars: $0,2 \mathrm{~mm}$. 


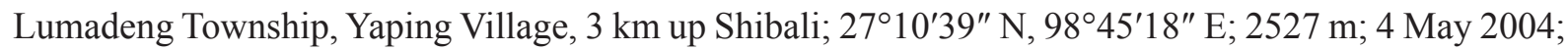
H.M. Yan and G.X. Peng leg.; HNU-20040504-2 • 1 ภ, 5 우; Lumadeng Township, Yaping Village, $7.2 \mathrm{~km}$ up of Shibali; $27^{\circ} 10^{\prime} 47^{\prime \prime}$ N, 98 $8^{\circ} 43^{\prime} 35^{\prime \prime}$ E; alt. 3059 m; 4 May 2004; H.M. Yan and G.X. Peng leg.; HNU-20040504-3 • 1 क; Lumadeng Township, Yaping Village; $27^{\circ} 10^{\prime} 39^{\prime \prime}$ N, 98 $45^{\prime} 18^{\prime \prime}$ E; alt.

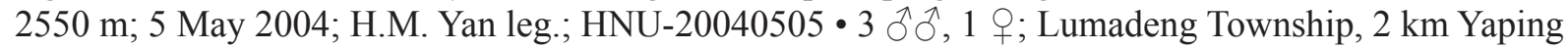
to Fugong; $27^{\circ} 10^{\prime} 39^{\prime \prime}$ N, 98 $45^{\prime} 18^{\prime \prime}$ E; alt. 2500 m; 7 May 2004; H.M. Yan leg.; HNU-20040507-1 - 1 웅 Lumadeng Township, Yaping Village; $27^{\circ} 08^{\prime} 42^{\prime \prime}$ N, 98 48'52" E; alt. 2530 m; 7 May 2004; H.M. Yan leg.; HNU-20040507-2 • 1 ô, 1 q; Lumadeng Township, near Shibali forest station; $27^{\circ} 10^{\prime} 08^{\prime \prime} \mathrm{N}$, 98 46'19" E; alt. 2650 m; 9 May 2004; Charles Griswold and H.M. Yan leg.; HNU-CGY41 • 1 §, 6 우;

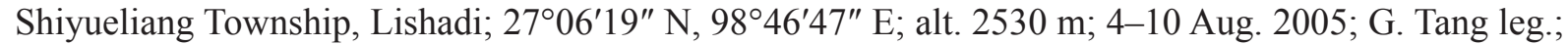

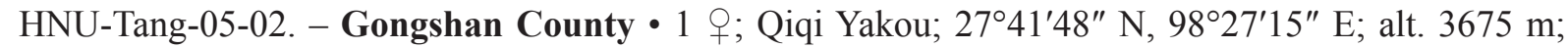
27 Sep. 2007; X.J. Peng leg.; HNU-20070927.

\section{Description}

Male (holotype)

Measurements. Total length 4.06. Prosoma 2.13 long, 1.66 wide; opisthosoma 2.29 long, 1.53 wide. Prosoma brown, with longitudinal dark brown band. Cervical grooves distinct, radial furrows indistinct (Fig. 1A). Eye sizes and interdistances: AME 0.14, ALE 0.16, PME 0.17, PLE 0.15; AME-AME 0.09, AME-ALE 0.11, PME-PME 0.08, PME-PLE 0.14, ALE-PLE 0.03. MOA anterior width 0.37, posterior width 0.41 , length 0.42 . Clypeus 0.10 high.

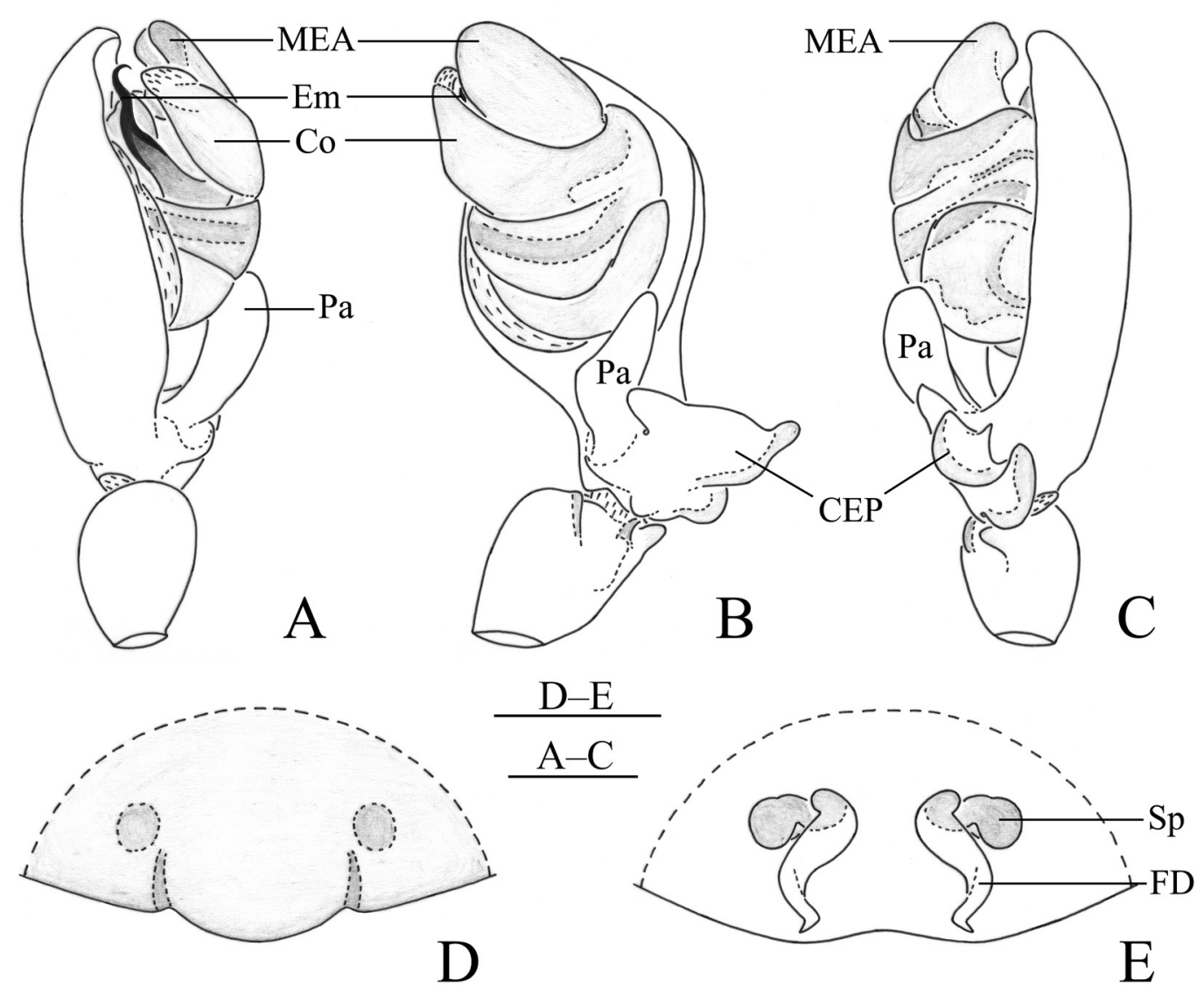

Fig. 4. Meta hamata sp. nov., left palp of holotype $\widehat{\partial}(\mathrm{A}-\mathrm{C})$; epigyne (D) and vulva (E) of paratype $q$ (HNU-CGY25): A. Prolateral view. B. Ventral view. C. Retrolateral view. D. Epigyne, ventral view. E. Vulva, front view. Scale bars: $0.2 \mathrm{~mm}$. 
Chelicerae. Strong, brown, with three promarginal and four retromarginal teeth.

GNATHOCOXAE. Dark brown, longer than wide.

LABIUM. Dark brown, as long as wide.

STERNUM. Dark brown, scutellate, with sparse dark brown hairs.

Legs. Brown, with annuli. Length of legs: I, 11.05 (3.05, 3.83, 2.95, 1.22); II, 8.38 (2.46, 2.91, 2.10, 0.91); III, 4.47 (1.42, 1.36, 1.13, 0.56); IV, 6.05 (1.96, 1.88, 1.52, 0.69). Leg formula: 1243.

Opisthosoma. Oval, with two pairs of sigillae. Both dorsum and venter yellowish brown, with black markings (Fig. 1A).

Palp (Figs 2, 4A-C). Cymbial ectobasal process simple, with two rounded ends in retrolateral view. Paracymbium finger-like, widest medially, with sparse long brown hairs. Metaine embolic apophysis tongue-shaped, extending forward.

EmBolus. Long, with hook-shaped tip. Conductor strong, arising meso-retrolaterally from bulb and extending clockwise, widest medially, with membranous end.

Female (CGY25, Fig. 1B)

MeAsurements. Total length 4.55. Prosoma 2.04 long, 1.62 wide; opisthosoma 2.81 long, 2.32 wide. Eye sizes and interdistances: AME 0.13, ALE 0.15, PME 0.16, PLE 0.14; AME-AME 0.11, AME-ALE 0.13, PME-PME 0.09, PME-PLE 0.16, ALE-PLE 0.03. MOA anterior width 0.35, posterior width 0.40, length 0.42. Clypeus 0.08 high.

LeGs. Length of legs: I, 8.67 (2.45, 3.06, 2.08, 1.08); II, 6.78 (2.01, 2.34, 1.57, 0.86); III, 3.83 (1.19, 1.21, $0.87,0.56)$; IV, $5.20(1.66,1.70,1.23,0.61)$. Leg formula: 1243 . Other morphological characteristics same as in male.

Epigyne (Figs 3, 4D-E). Posterior margin of epigynal plate round, looks like smiling face in ventral view. Spermathecae small and like a boxing glove. Fertilization ducts thick, S-shaped.

\section{Variation}

The total length in male specimens examined ranges from 3.60 to 4.06 , in female specimens from 4.26 to 4.90 .

\section{Distribution}

China, Yunnan Province (Fugong, Gongshan) (Fig. 16).

Meta longlingensis sp. nov. urn:1sid:zoobank.org:act:C7F51E0B-06E5-42C1-AD06-ECAA8A703CE6

Figs 1I, 5-6

\section{Differential diagnosis}

Meta longlingensis sp. nov. can be distinguished from the other Chinese Meta species by the hookshaped tip of the cymbial ectobasal process of the male palp (Figs 5-6). This new species resembles M. yinae sp. nov. (Figs 13-15), but can be distinguished from the latter by the following chararacters. Cymbial ectobasal process without the spine-like apophysis in ventral view found in that of M. yinae 


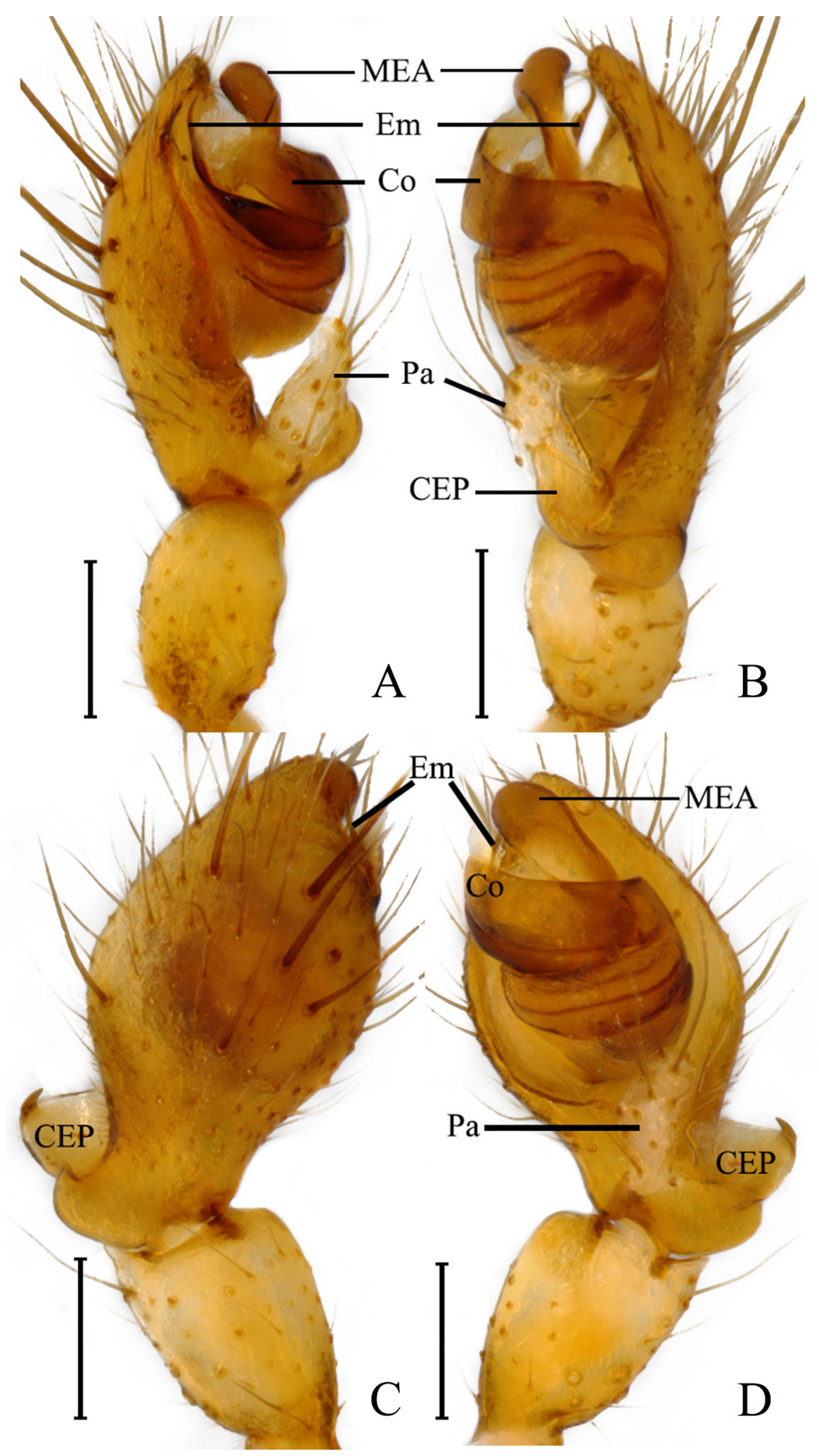

Fig. 5. Meta longlingensis sp. nov. Left palp of holotype $ð$ (HNU-Tang031029). A. Prolateral view. B. Retrolateral view. C. Dorsal view. D. Ventral view. Scale bars: $0.2 \mathrm{~mm}$. 
sp. nov. (Figs 5D, 6B, 13D, 15B). In prolateral view, terminal portion of embolus arc-shaped, slightly covered by conductor in $M$. longlingensis (Figs 5A, 6A), erect and passing through conductor in $M$. yinae sp. nov. (Figs 13A, 15A). In retrolateral view, metaine embolic apophysis wider anteriorly in $M$. longlingensis (Figs 5D, 6B), wider medially in M. yinae sp. nov. (Figs 13D, 15B).

\section{Etymology}

The specific name refers to the type locality.

\section{Type material}

\section{Holotype}

CHINA - 1 \’; Yunnan Province, Longling County, Xiaoheishan Village (National 320 Road); 24³0'13" N, 98²7'25" E; alt. 2106 m; 29 Oct. 2003; G. Tang leg.; HNU-Tang031029.

\section{Description}

\section{Male (holotype)}

MeAsurements. Total length 4.02. Prosoma 1.90 long, 1.48 wide; opisthosoma 2.08 long, 1.06 wide. Cervical groove distinct, radial furrows indistinct. Eye sizes and interdistances: AME 0.12, ALE 0.15, PME 0.16, PLE 0.13; AME-AME 0.11, AME-ALE 0.08, PME-PME 0.06, PME-PLE 0.12, ALE-PLE 0.04. MOA 0.40 long, front width 0.32 , back width 0.39. Clypeus 0.09 high.

Chelicerae. Strong, yellowish brown, with three promarginal and four retromarginal teeth.

GNathocoXaE AND LABIUM. Yellowish brown, longer than wide.

STERNUM. Brown, scutellate, with sparse brown hairs.

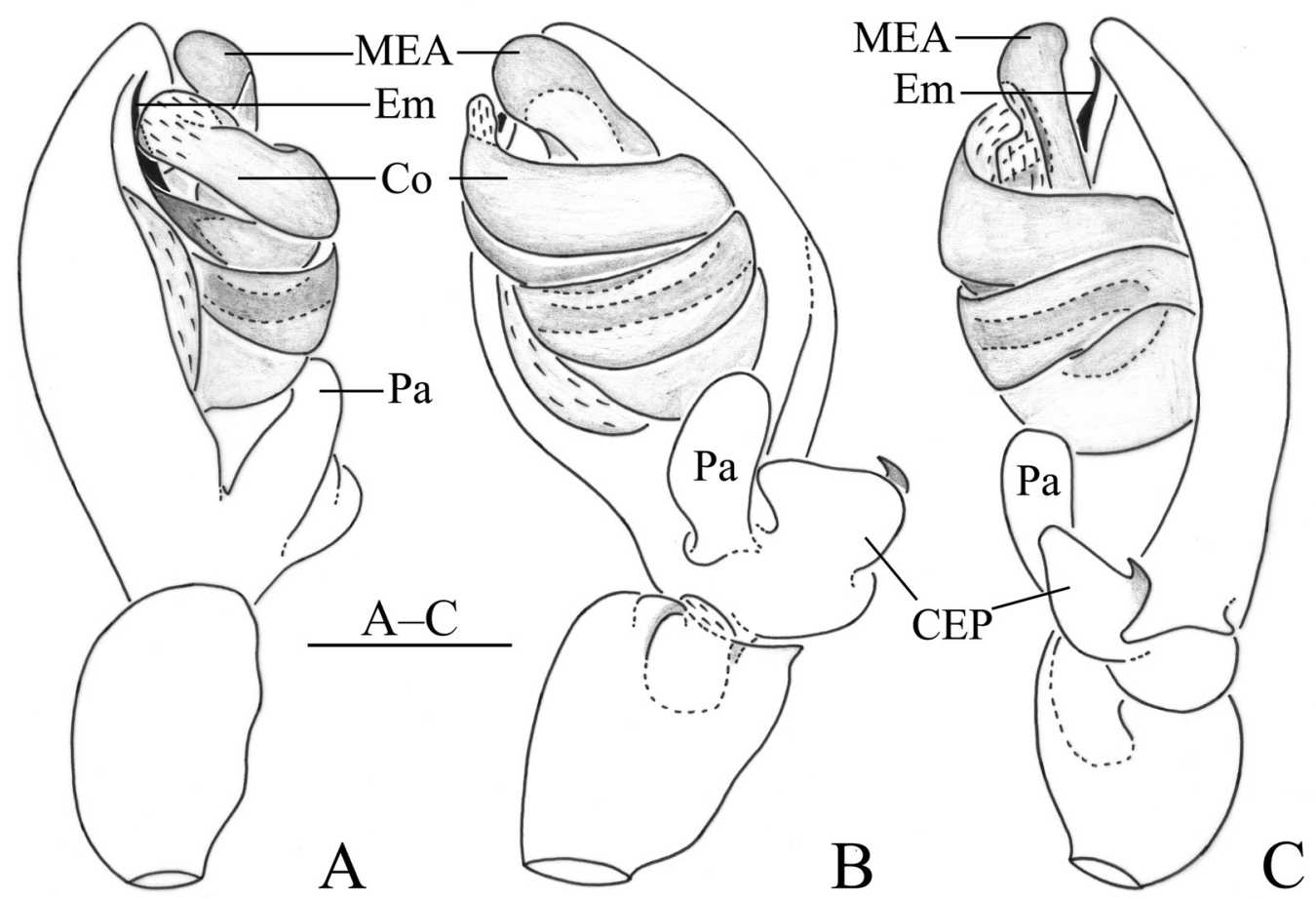

Fig. 6. Meta longlingensis sp. nov. Left palp of holotype $\lesssim$ (HNU-Tang031029). A. Prolateral view. B. Ventral view. C. Retrolateral view. Scale bars: $0.2 \mathrm{~mm}$. 
LEGs. Brown, with annuli. Length of legs: I, 15.42 (4.19, 5.30, 4.53, 1.40); II, 10.56 (3.13, 3.59, 2.84, 1.00); III, 5.17 (1.71, 1.57, 1.28, 0.61); IV, 7.85 (2.41, 2.64, 2.07, 0.73).Leg formula: 1243.

Opisthosoma. Oval.

Dorsum. With two pairs of sigillae, yellowish brown, proximally with a white band followed by irregular black markings posteriorly (Fig. 1I). Venter of opisthosoma yellowish brown, with black markings. Dorsum of prosoma yellowish brown, with longitudinal dark brown band (Fig. 1I).

PaLP (Figs 5-6). Cymbial ectobasal process wider than long, with hook-shaped tip. Paracymbium bulblike, with a narrow base and sparse long, brown hairs. Metaine embolic apophysis ventrally grooved, with broad, round end.

EmBoLus. Long, distal portion needle-shaped, extending forward. Conductor longer than wide, slightly curved, arising meso-retrolaterally from bulb and extending clockwise, with a membranous end.

\section{Female}

Unknown.

\section{Distribution}

China, Yunnan Province (Longling) (Fig. 16).

Meta tangi sp. nov.

urn:lsid:zoobank.org:act:10D52C59-FE5E-4351-840F-33980B2AF94B

Figs $1 \mathrm{C}-\mathrm{D}, 7-9$

\section{Differential diagnosis}

Meta tangi sp. nov. can be distinguished from the other Chinese Meta species by having a thin and long embolus, a dagger-shaped cymbial ectobasal process of the male palp (Figs 7, 9A-C), and U-shaped spermathecae of its epigyne (Figs 8B, 9E). This new species resembles M. hamata sp. nov. (Figs 1A-B, 2-4), but can be distinguished by the following characters. Cymbial ectobasal process longer than wide with pointed end in ventral view in $M$. tangi sp. nov. (Figs 7D, 9B), wider than long in M. hamata sp. nov. (Figs 2D, 4B). Distal part of embolus thin and proximally covered by the conductor in prolateral view in M. tangi sp. nov. (Figs 7A, 9A), thick and not covered by the conductor in M. hamata sp. nov. (Figs 2A, 4A). Metaine embolic apophysis narrow in ventral view in $M$. tangi sp. nov. (Figs 7D, 9B), tongue-like in M. hamata sp. nov. (Figs 2D, 4B). Spermathecae U-shaped in M. tangi sp. nov. (Figs 8B, 9E), boxing glove-like in M. hamata sp. nov. (Figs 3B, 4E).

\section{Etymology}

The specific name is a patronym dedicated to Mr. Guo Tang, one of the collectors of the type specimens.

\section{Type material}

\section{Holotype}

CHINA - ${ }^{\lambda}$; Yunnan Province, Baoshan City, Longyang District, Mangkuan Township, Baihualing; $25^{\circ} 18^{\prime} 13^{\prime \prime}$ N, 9848'01" E; alt. 1624 m; 10 Oct. 2007; X.J. Peng leg.; HNU-20071010.

Paratypes $(11 \delta \hat{\delta} \widehat{\delta}$ and 9 우 $)$

CHINA - Yunnan Province • 1 đ̇; same collection data as for holotype; HNU-20071010 • 2 우; Tengchong County, Jietou Township, Shaba Village, Lijiazai Group; $25^{\circ} 14^{\prime} 11^{\prime \prime}$ N, 98 $25^{\prime} 16^{\prime \prime}$ E; alt. 
1819 m; 23 Oct. 2003; G. Tang leg.; HNU-Tang031023 • 3 ô ô; Baoshan City, Nankang Yakou (National

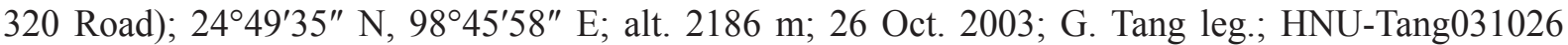

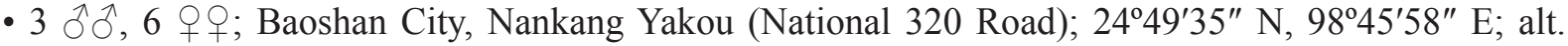
2186 m; 30 Oct. 2003; G. Tang leg.; HNU-Tang031030 • 3 ô ô; Baoshan City, Nankang Yakou (National 320 Road); 2449'35" N, 9845'58" E; alt. 2186 m; 31 Oct. 2003; G. Tang leg.; HNU-Tang031031 • 1 क;

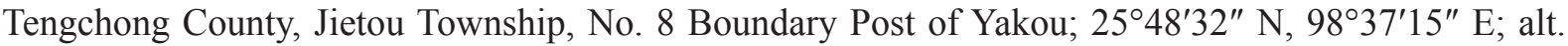
2890 m; 23 May 2006; X.J. Peng, X.P. Wang and P. Hu leg.; HNU-Wang060523 • 1 §; Longyang

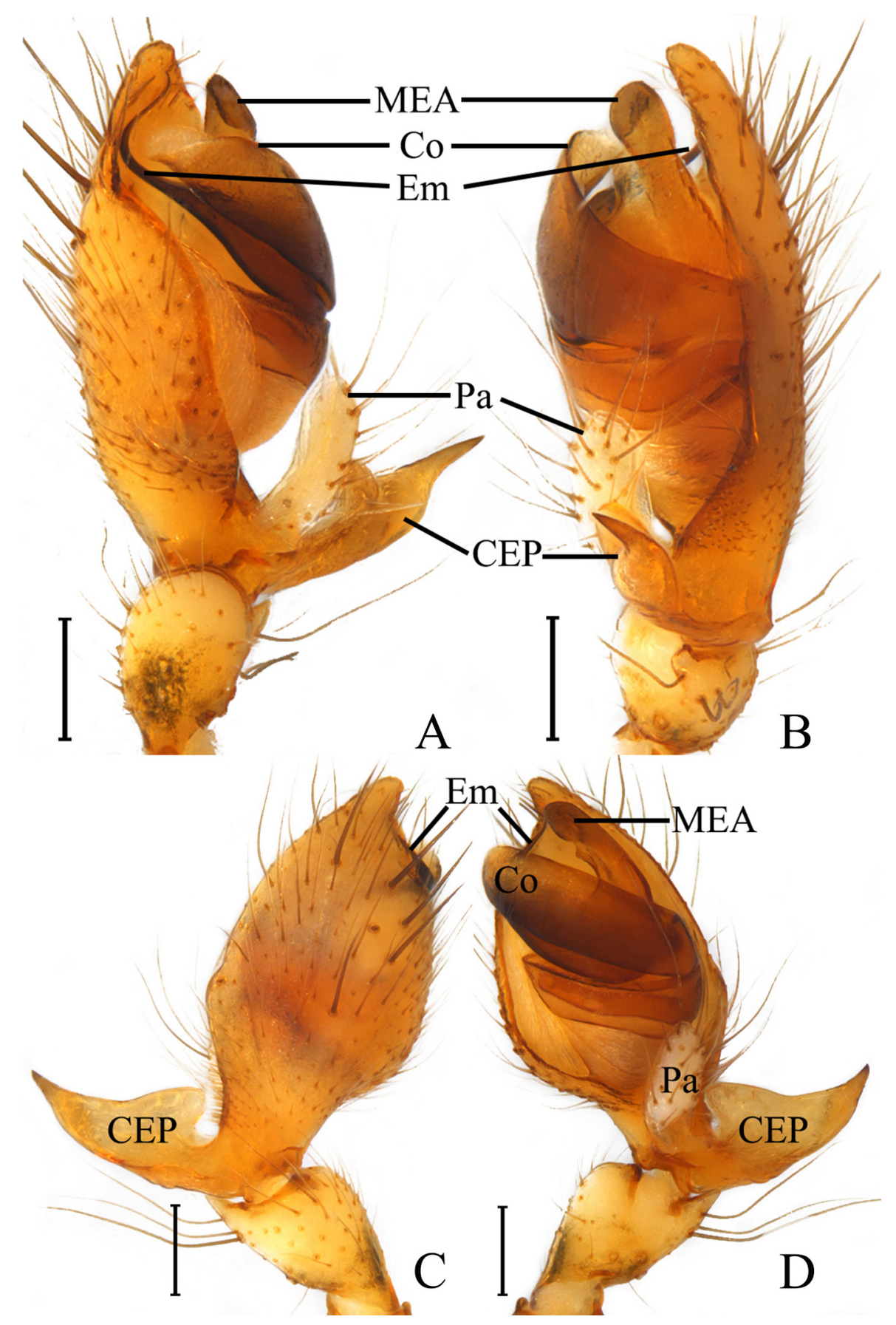

Fig. 7. Meta tangi sp. nov. Left palp of holotype $\hat{\jmath}$ (HNU-20071010). A. Prolateral view. B. Retrolateral view. C. Dorsal view. D. Ventral view. Scale bars: $0.2 \mathrm{~mm}$. 


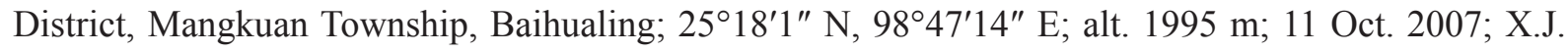
Peng leg.; HNU-20071011.

\section{Description}

Male (holotype, Fig. 1C)

Measurements. Total length 5.33. Prosoma 2.52 long, 1.86 wide; opisthosoma 3.10 long, 2.02 wide. Eye sizes and interdistances: AME 0.12, ALE 0.15, PME 0.14, PLE 0.14; AME-AME 0.14, AME-ALE 0.16, PME-PME 0.11, PME-PLE 0.18, ALE-PLE 0.05. MOA 0.41 long, front width 0.39, back width 0.44 . Clypeus height 0.13 .

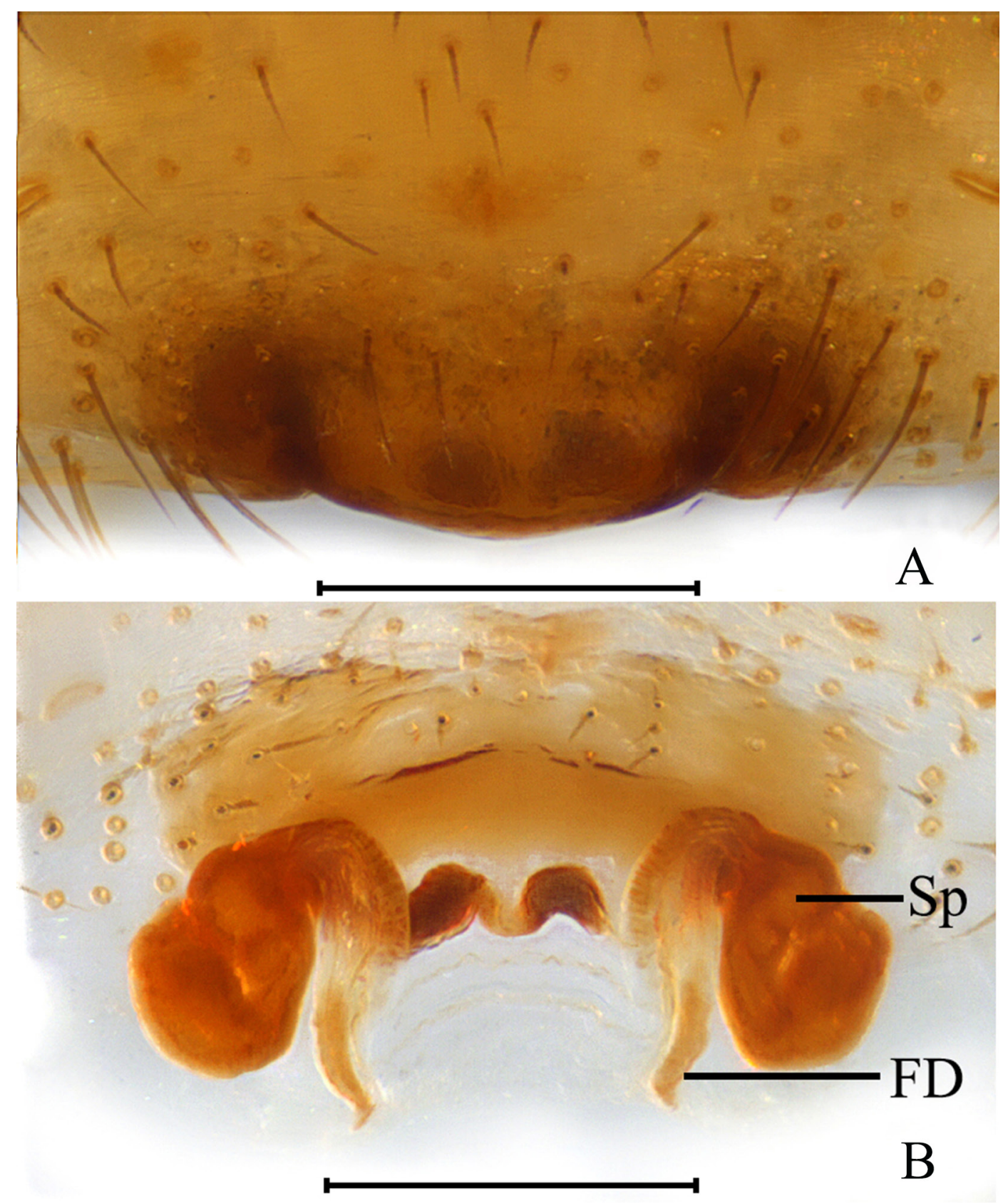

Fig. 8. Meta tangi sp. nov. Paratype $\uparrow$ (HNU-20071010). A. Epigyne, ventral view. B. Vulva, front view. Scale bars: $0,2 \mathrm{~mm}$. 
Chelicerae. Strong, yellowish brown, three promarginal and four retromarginal teeth.

GnAthocoXae AND LABium. Brown, longer than wide. Sternum brown, scutellate, with sparse dark brown hairs.

Legs. Yellowish brown, with annuli. Length of legs: I, 16.77 (4.45, 6.01, 4.70, 1.61); II, 12.07 (3.57, 4.26, 3.16, 1.08); III, 5.96 (1.92, 1.91, 1.47, 0.66); IV, 8.77 (2.73, 2.74, 2.46, 0.84). Leg formula: 1243.

Opisthosoma. Oval.

DoRsum. With two pairs of sigillae, yellowish brown, proximally with a white band followed by irregular black markings posteriorly (Fig. 1C). Venter of opisthosoma yellowish brown, with black markings. Dorsum of prosoma yellowish brown, with longitudinal dark brown band. Cervical groove distinct, radial furrows indistinct (Fig. 1C).

Palp (Figs 7, 9A-C). Cymbial ectobasal process dagger-like. Paracymbium rod-like and curved, with sparse long, brown hairs. Metaine embolic apophysis long, narrow, finger-like.

Embolus. Long, thin, most of proximal portion covered by conductor. Conductor arising mesoretrolaterally from bulb, extending clockwise, with a membranous end.

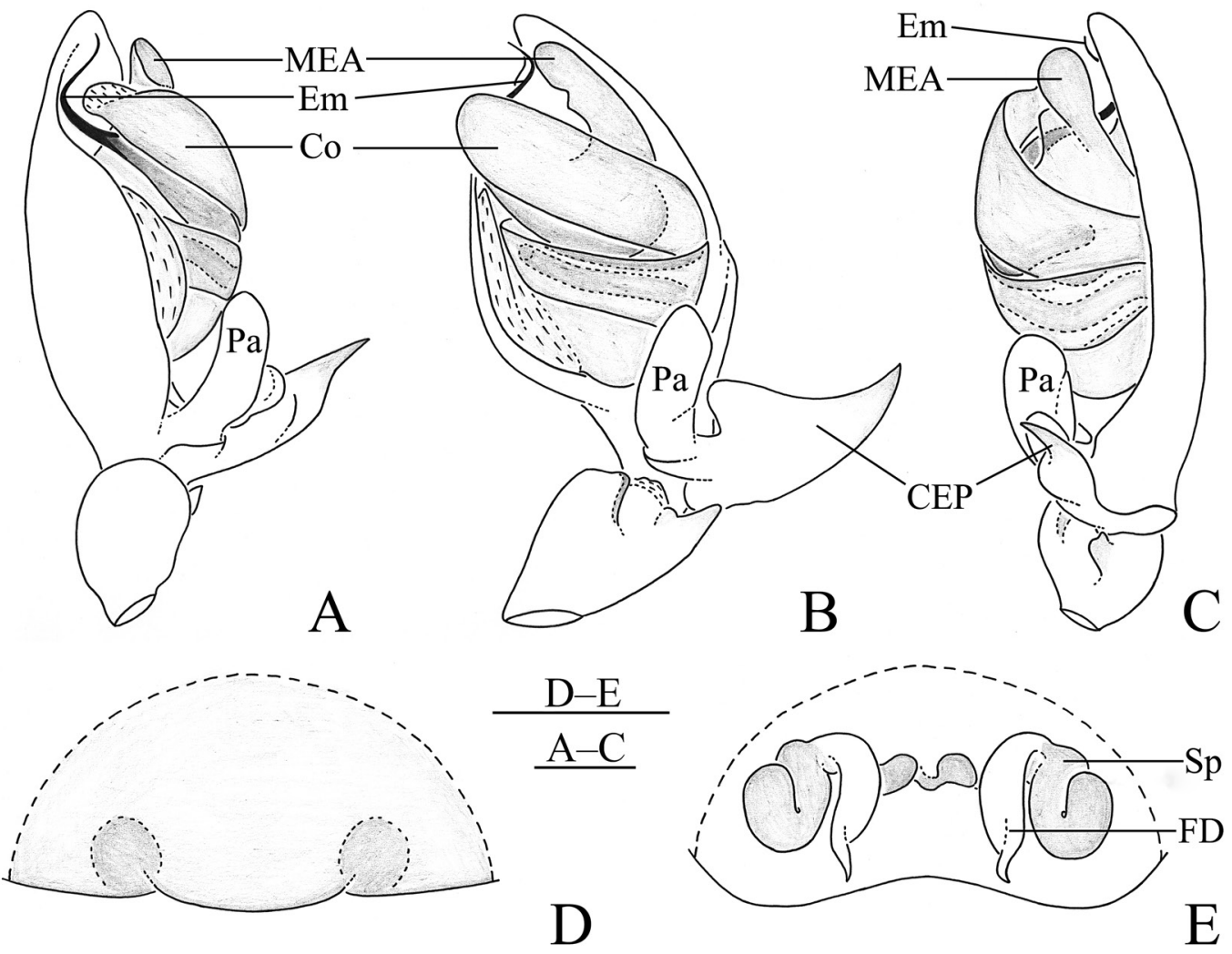

Fig. 9. Meta tangi sp. nov. Left palp of holotype $\delta^{\lambda}(\mathrm{A}-\mathrm{C})$; epigyne (D) and vulva (E) of paratype $q$ (HNU-20071010). A. Prolateral view. B. Ventral view. C. Retrolateral view. D. Epigyne, ventral view E. Vulva, front view. Scale bars: $0.2 \mathrm{~mm}$. 
Female (Tang031023, Fig. 1F)

Measurements. Total length 5.50. Prosoma 2.03 long, 1.59 wide; opisthosoma 3.73 long, 3.09 wide (Fig. 1D). Eye sizes and interdistances: AME 0.11, ALE 0.15, PME 0.15, PLE 0.14; AME-AME 0.10, AME-ALE 0.11, PME-PME 0.09, PME-PLE 0.13, ALE-PLE 0.04. MOA 0.40 long, front width 0.34, back width 0.40 . Clypeus 0.07 high.

LEGs. Length of legs: I, 10.26 (3.08, 3.48, 2.62, 1.08); II, 7.76 (2.30, 2.74, 1.80, 0.92); III, 4.28 (1.33, 1.33, $1.02,0.60)$; IV, $6.28(2.11,1.97,1.51,0.69)$. Leg formula: 1243. Other morphological characteristics same as in male.

EpIGYNE (Figs 8, 9D-E). Spermathecae U-shaped. Fertilization ducts long, thick, sickle-shaped.

\section{Variation}

The total length in male specimens examined ranges from 4.82 to 5.33 , in female specimens from 5.50 to 6.67 .

\section{Distribution}

China, Yunnan Province (Baoshan, Tengchong) (Fig. 16).

$$
\begin{aligned}
& \text { Meta yani sp. nov. } \\
& \text { urn:lsid:zoobank.org:act:D59B312C-31B9-45DC-B8BD-2B647DDCA724 }
\end{aligned}
$$

Figs 1E-F, 10-12

\section{Differential diagnosis}

Meta yani sp. nov. can be distinguished from the other Chinese Meta species by the wide and bifurcated metaine embolic apophysis of the male palp (Figs 10D, 12B) and the long fertilization ducts of its epigyne (Figs 11B, 12E). Meta yani sp. nov. resembles M. yinae sp. nov. (Figs 13-15), but can be distinguished from the latter by the following characters. Metaine embolic apophysis bifurcated in ventral view in M. yani sp. nov. (Figs 10D, 12B), not bifurcated in M. yinae sp. nov. (Figs 13D, 15B). The spine-like apophysis of the cymbial ectobasal process arises from the median portion of CEP and is pointed towards the cymbium in M. yani sp. nov. (Figs 10B, 12C), whereas it forms the top of CEP and is pointed towards the genital bulb in M. yinae sp. nov. (Figs 13B, 15C). The posterior margin of the epigynal plate is centrally incised in M. yani sp. nov. (Figs 11A, 12D), whereas it is almost round in M. yinae sp. nov. (Figs 14A, 15D). Spermathecae horizontal, with boxing glove-like shape in M. yani sp. nov. (Figs 11B, 12E), longitudinal in M. yinae sp. nov. (Figs $14 \mathrm{~B}, 15 \mathrm{E})$.

\section{Etymology}

The specific name comes from the family name of the collector, Prof. Yan Heng-mei; noun.

\section{Type material}

\section{Holotype}

CHINA -1 \} \text { ; Yunnan Province, Gongshan County, Cikai Township, Dabadi to Gongshan, along Pula } river; $27^{\circ} 47^{\prime} 40^{\prime \prime}$ N, 98³0'25" E; 3025-3990 m; 4 Oct. 2002; H.M. Yan leg.; HNU-Yan021004.

\section{Paratypes}

CHINA・2 ふぇ, 5 우; same collection data as for holotype; HNU-Yan021004. 


\section{Description}

Male (holotype, Fig. 1E)

Measurements. Total length 4.14. Prosoma 1.92 long, 1.58 wide; opisthosoma 2.41 long, 2.29 wide. Eye sizes and interdistances: AME 0.08, ALE 0.11, PME 0.12, PLE 0.11; AME-AME 0.14, AME-ALE 0.14, PME-PME 0.12, PME-PLE 0.18, ALE-PLE 0.06. MOA 0.37 long, front width 0.32, back width 0.36. Clypeus 0.09 high.

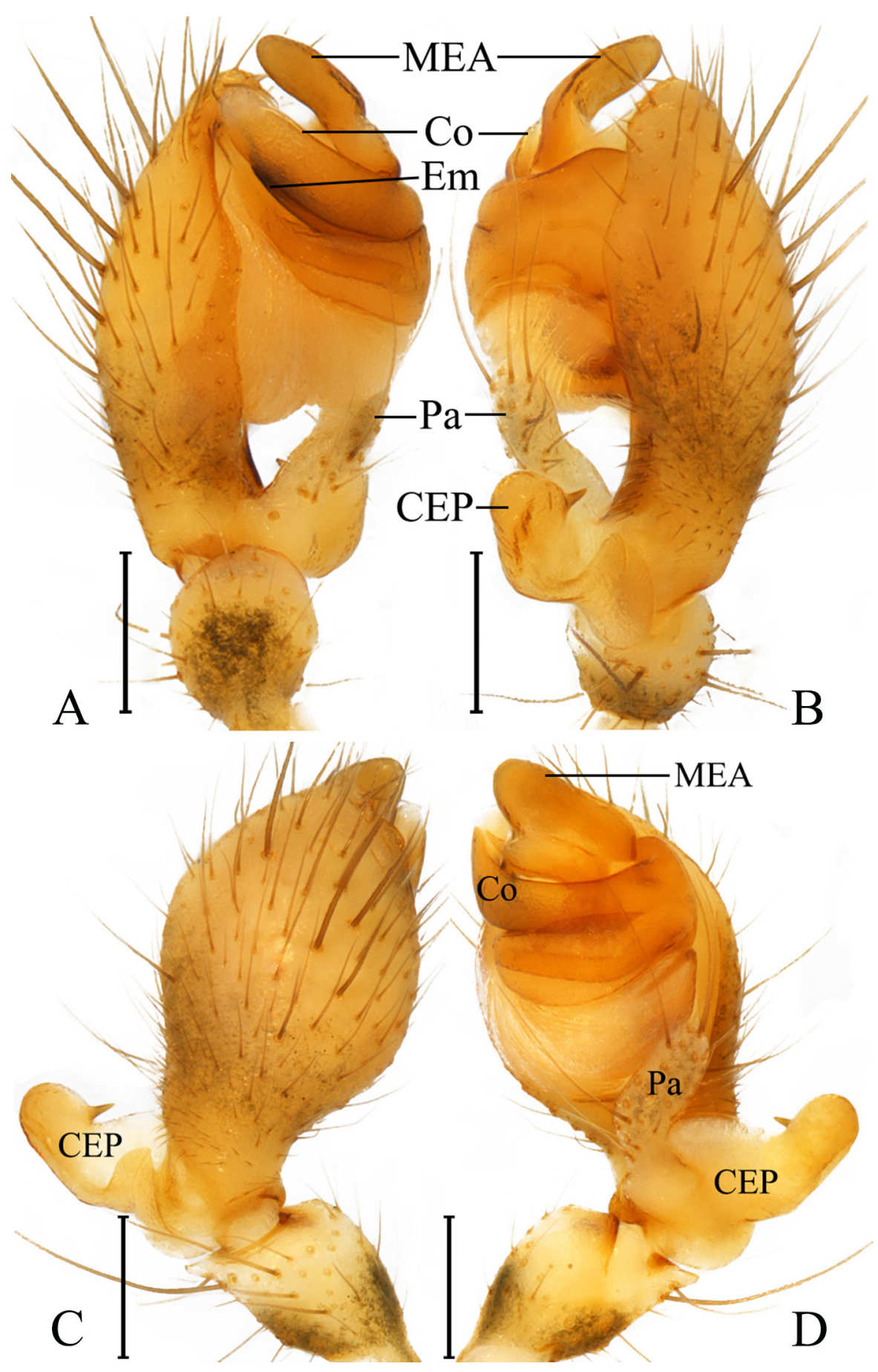

Fig. 10. Meta yani sp. nov. Left palp of holotype $\widehat{\jmath}$ (HNU-Yan021004). A. Prolateral view. B. Retrolateral view. C. Dorsal view. D. Ventral view. Scale bars: $0.2 \mathrm{~mm}$. 
CheliCerae. Strong, yellowish brown, three promarginal and four retromarginal teeth.

Gnathocoxae And Labium. Gray brown, longer than wide. Sternum gray brown, scutellate, with sparse brown hairs.

Dorsum of PRosoma. Yellowish brown, with longitudinal dark brown band. Cervical groove distinct, radial furrows indistinct (Fig. 1E).
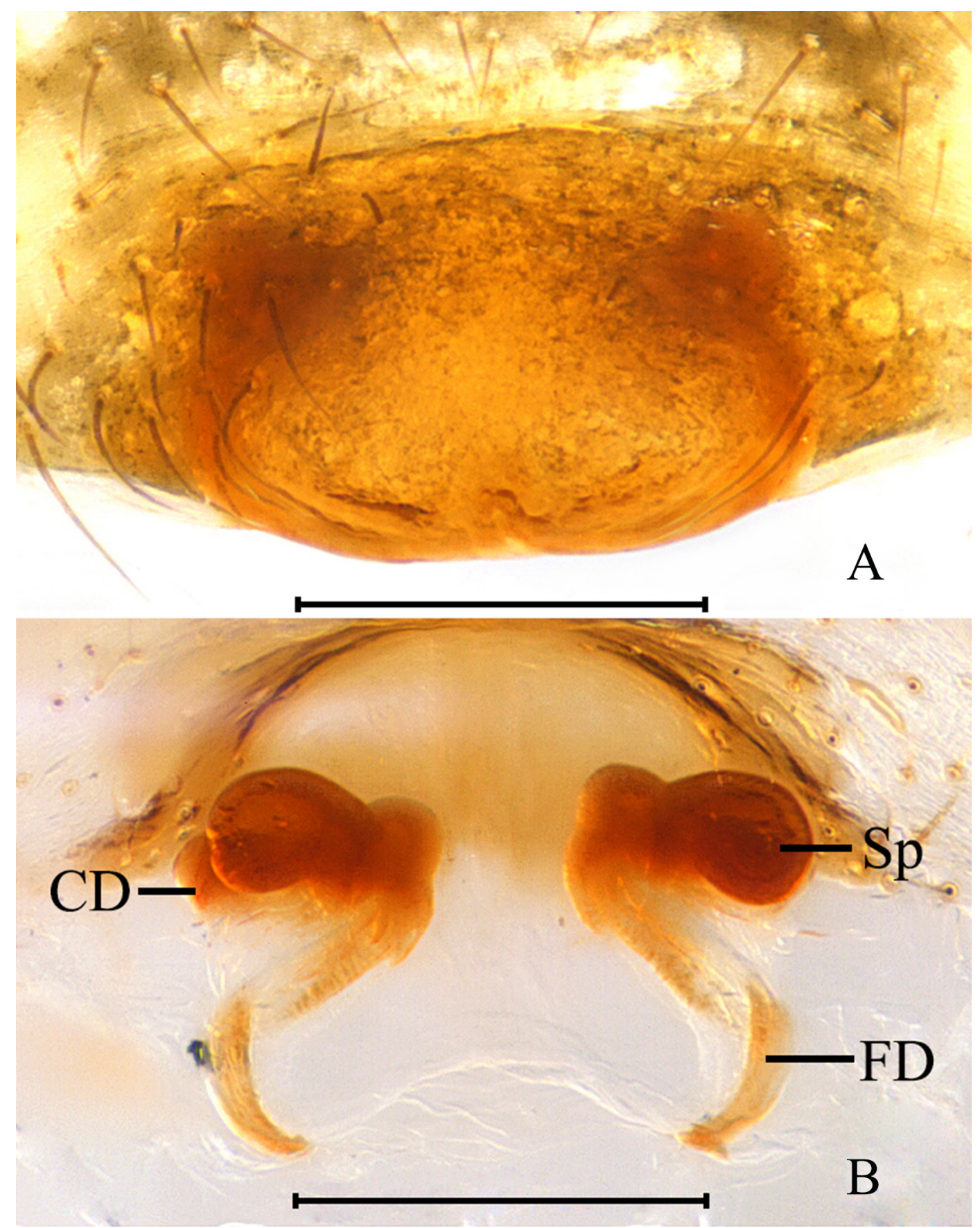

Fig. 11. Meta yani sp. nov. Paratype $q$ (HNU-Yan021004). A. Epigyne, ventral view. B. Vulva, front view. Scale bars: $0.2 \mathrm{~mm}$. 
LEGs. Yellowish brown, with annuli. Length of legs: I, 10.00 (2.79, 3.51, 2.64, 1.06); II, 7.72 (2.24, 2.68, 1.93, 0.87); III, 4.36 (1.39, 1.39, 1.00, 0.58); IV, 5.61 (1.80, 1.78, 1.42, 0.61). Leg formula: 1243.

Opisthosoma. Ovate, dorsum with two pairs of sigillae, yellowish brown, with irregular black and white markings (Fig. 1E). Venter of opisthosoma yellowish brown, with black markings.

PaLP (Figs 10, 12A-C). Cymbial ectobasal process Y-shaped, with a small tooth ventro-laterally. Paracymbium short, rod-like, with sparse long, brown hairs. Metaine embolic apophysis bifurcated in ventral view. Embolus long, thin, most of proximal portion covered by conductor. Conductor longer than wide, arising meso-retrolaterally from bulb, extending clockwise, with a membranous end.

Female (Yan021004, Fig. 1F)

Measurements. Total length 4.00. Prosoma 1.85 long, 1.46 wide; opisthosoma 2.35 long, 1.96 wide (Fig. 1F). Eye sizes and interdistances: AME 0.12, ALE 0.14, PME 0.14, PLE 0.14; AME-AME 0.08, AME-ALE 0.10, PME-PME 0.08, PME-PLE 0.13, ALE-PLE 0.03. MOA 0.38 long, front width 0.31, back width 0.37 . Clypeus 0.07 high.

LEGS. Length of legs: I, 7.71 (2.18, 2.67, 1.92, 0.94); II, 6.05 (1.77, 2.00, 1.50, 0.78); III, 3.66 (1.13, 1.18, $0.79,0.56)$; IV, $4.83(1.54,1.59,1.11,0.59) . L e g$ formula: 1243 . Other morphological characteristics same as in male except lightly colored.

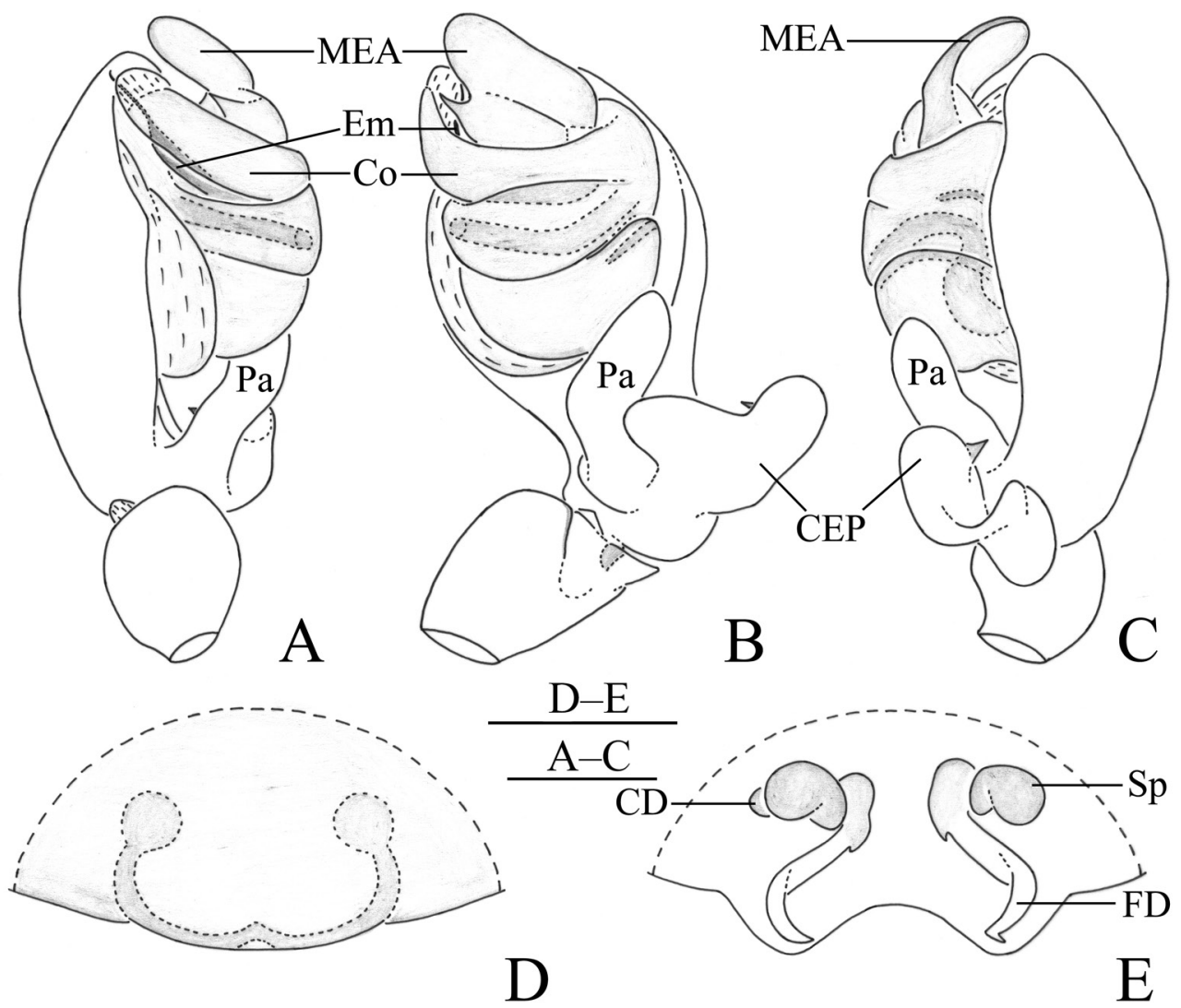

Fig. 12. Meta yani sp. nov. Left palp of holotype $\widehat{\diamond}(\mathrm{A}-\mathrm{C})$; epigyne (D) and vulva (E) of paratype ㅇ (HNU-Yan021004). A. Prolateral view. B. Ventral view. C. Retrolateral view. D. Epigyne, ventral view. E. Vulva, front view. Scale bars: $0.2 \mathrm{~mm}$. 
Epigyne (Figs 11, 12D-E). Spermathecae small, shape boxing glove-like. Fertilization ducts long, slightly curved.

\section{Variation}

The total length in male specimens examined ranges from 4.11 to 4.56 , in female specimens from 3.57 to 4.34 .

\section{Distribution}

China, Yunnan Province ( Gongshan) (Fig. 16).

$$
\begin{aligned}
& \text { Meta yinae sp. nov. } \\
& \text { urn:1sid:zoobank.org:act:07066DE2-94F3-431C-A28C-5ED596CA782B }
\end{aligned}
$$

Figs $1 \mathrm{G}-\mathrm{H}, 13-15$

\section{Differential diagnosis}

Meta yinae sp. nov. can be distinguished from the other Chinese Meta species by the wide conductor, the Y-shaped cymbial ectobasal process of the male palp (Figs 13, 15A-C), and the bean-shaped spermathecae of the epigyne (Figs 14B, 15E). Meta yinae sp. nov. resembles M. yani sp. nov. (Figs 1012), but can be distinguished from the latter by the following characters. Metaine embolic apophysis not bifurcated in ventral view in M. yinae sp. nov. (Figs 13D, 15B), bifurcated in M. yani sp. nov. (Figs 10D, 12B). The spine-like apophysis of the cymbial ectobasal process arises from the top of CEP and points towards the genital bulb in M. yinae sp. nov. (Figs 13B, 15C), it forms the median portion of CEP and points towards the cymbium in M. yani sp. nov. (Figs 10B, 12C). The posterior margin of the epigynal plate almost round in M. yinae sp. nov. (Figs 14A, 15D), centrally incised in M. yani sp. nov. (Figs 11A, 12D). Spermathecae longitudinal, present posteriorly in M. yinae sp. nov. (Figs 14B, 15E), whereas horizontal, present anteriorly in M. yani sp. nov. (Figs 11B, 12E).

\section{Etymology}

The specific epithet is taken from the family name of Prof. Changmin Yin, in honour of her great contribution to Chinese arachnology; noun.

\section{Type material}

\section{Holotype}

CHINA - Ō; Yunnan Province, Fugong County, Pihe Township, Yueliangtian Village; $26^{\circ} 34^{\prime} 04^{\prime \prime} \mathrm{N}$, 9854'32" E; alt. 1520 m; 20-24 Aug. 2005; G. Tang leg.; HNU-Tang-05-08.

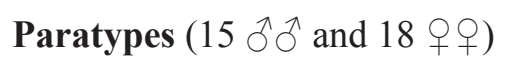

CHINA - Yunnan Province - Fugong County • $7 \widehat{\partial}, 13$ क $q$; same collection data as for holotype; HNU-Tang-05-08 • $1 \delta^{\top}$; Lumadeng Township, Yaping Village, $7.2 \mathrm{~km}$ up of Shibali; $27^{\circ} 10^{\prime} 47^{\prime \prime} \mathrm{N}$, 98 43'35" E; alt. 3059 m; 4 May 2004; H.M. Yan and G.X. Peng leg.; HNU-20040504-3 • 1 ठ, 3 q $ᄋ$; 10.1-11.5 km from Shibali to Yaping; $27^{\circ} 12^{\prime} 02^{\prime \prime}$ N, 98 $42^{\circ} 49^{\prime \prime}$ E-27 $12^{\prime} 24^{\prime \prime}$ N, $98^{\circ} 43^{\prime} 03^{\prime \prime}$ E; alt. 32253290 m; 8 May 2004; C. Griswold and D.H. Kavanaugh leg.; HNU-CGY40 • 1 ; L Lumadeng Township, Yaping Village, Yaping Yakou; $27^{\circ} 10^{\prime} 47^{\prime \prime}$ N, 98 $8^{\circ} 43^{\prime} 35^{\prime \prime}$ E; alt. 3280-3100 m; 8 May 2004; H.M. Yan

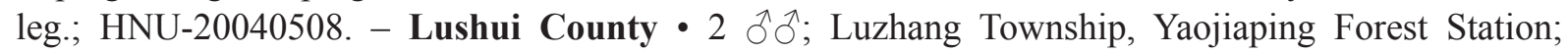
$25^{\circ} 58^{\prime} 31^{\prime \prime}$ N, 9842'36" E; alt. 2515 m; 20 May 2005; K.J. Guo leg.; HNU-GKJ013. - Longyang County

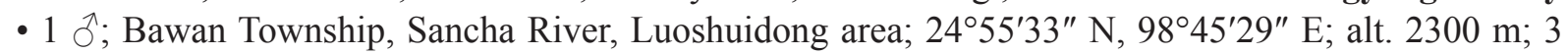
June 2005; Charles Griswold leg.; HNU-CGY137. - Tengchong County • 1 đ’; Jietou Township, No.

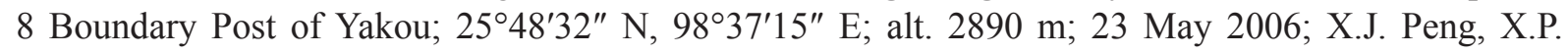




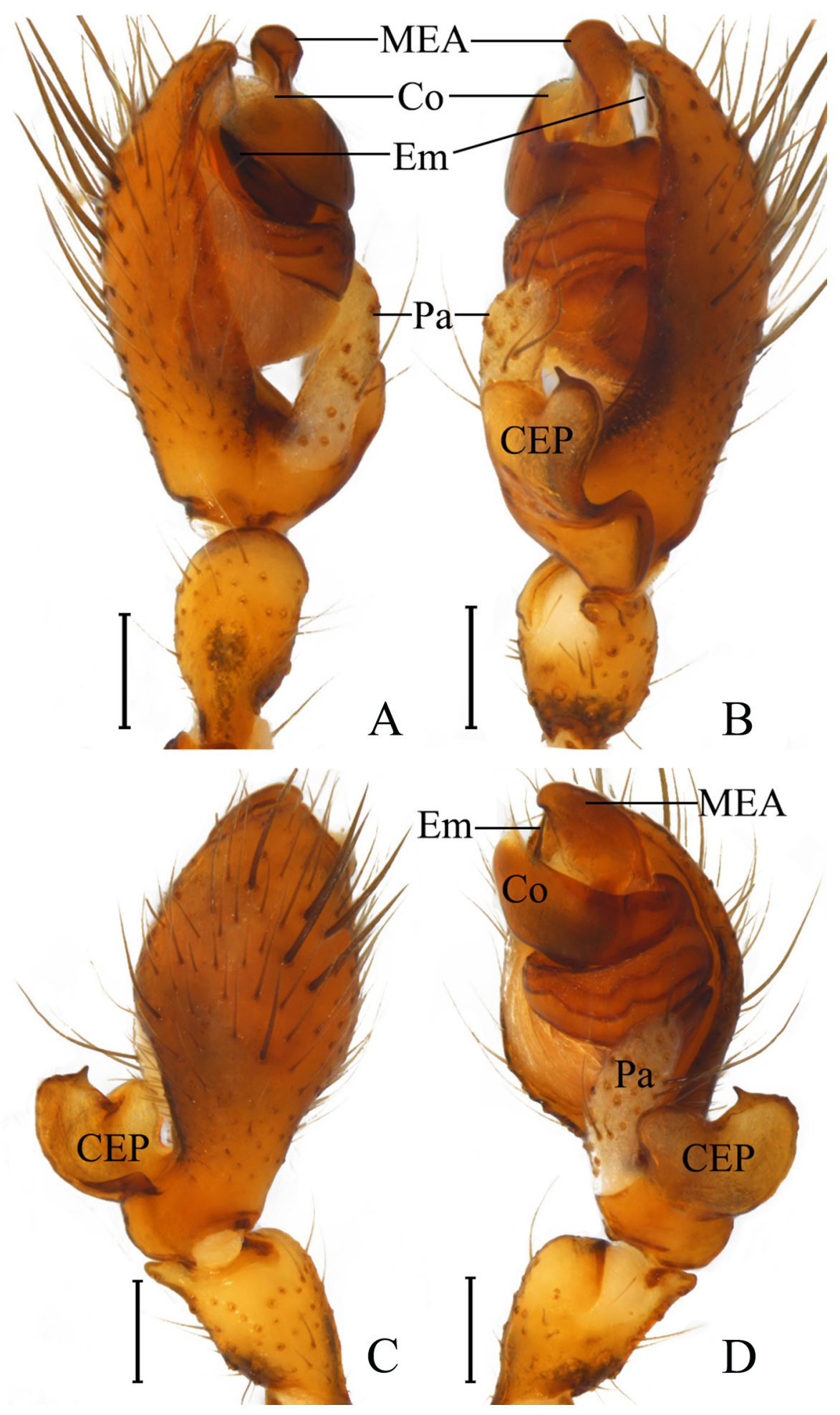

Fig. 13. Meta yinae sp. nov. Left palp of holotype $\widehat{\jmath}$ (HNU-Tang-05-08). A. Prolateral view. B. Retrolateral view. C. Dorsal view. D. Ventral view. Scale bars: $0.2 \mathrm{~mm}$. 
Wang and P. Hu leg.; HNU-Wang060523-2. - Gongshan County • 1 9 ; Cicai Township, Dahaituo;

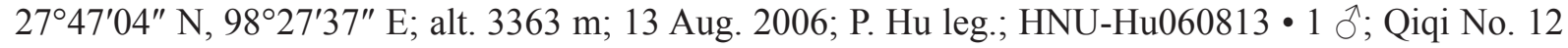
bridge; 2742'59" N, 98³0'11" E; alt. 2738 m; 28 Sep. 2007; X.J. Peng leg.; HNU-20070928 • 1 万’; Qiqi Dongshaofang; 2741'43" N, 98²9'07" E; alt. 3208 m; 29 Sep. 2007; X.J. Peng leg.; HNU-20070929.

\section{Description}

Male (holotype, Fig. 1G)
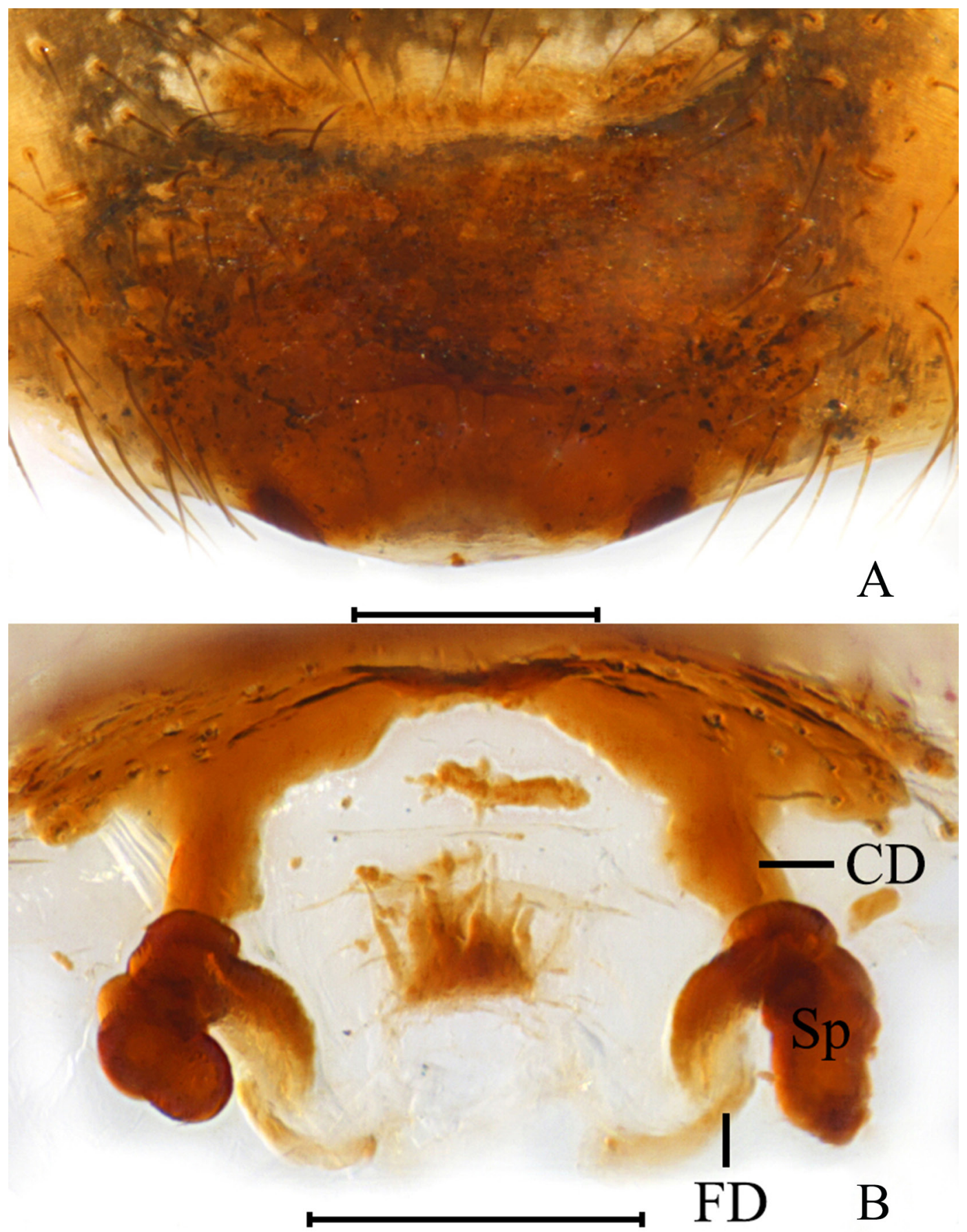

Fig. 14. Meta yinae sp. nov. Paratype $q$ (HNU-Tang-05-08). A. Epigyne, ventral view. B. Vulva, front view. Scale bars: $0.2 \mathrm{~mm}$. 
Measurements. Total length 5.29. Prosoma 2.45 long, 2.00 wide; opisthosoma 3.28 long, 1.95 wide. Eye sizes and interdistances: AME 0.14, ALE 0.16, PME 0.15, PLE 0.16; AME-AME 0.09, AME-ALE 0.13, PME-PME 0.09, PME-PLE 0.19, ALE-PLE 0.03. MOA 0.44 long, front width 0.37, back width 0.42. Clypeus 0.11 high.

Chelicerae. Strong, brown, with three promarginal and four retromarginal teeth.

Gnathocoxae AND Labium. Brown, longer than wide.

Dorsum of PRosoma. Yellowish brown, with longitudinal dark brown band. Cervical groove distinct, radial furrows indistinct (Fig. 1G).

Sternum. Brown, scutellate, with sparse brown hairs.

LeGs. Brown, with annuli. Length of legs: I, 13.40 (3.82, 4.68, 3.41, 1.49); II, 10.48 (3.02, 3.73, 2.51, 1.22); III, 6.00 (2.01, 1.89, 1.39, 0.71); IV, 7.71 (2.50, 2.45, 1.91, 0.85). Leg formula: 1243.

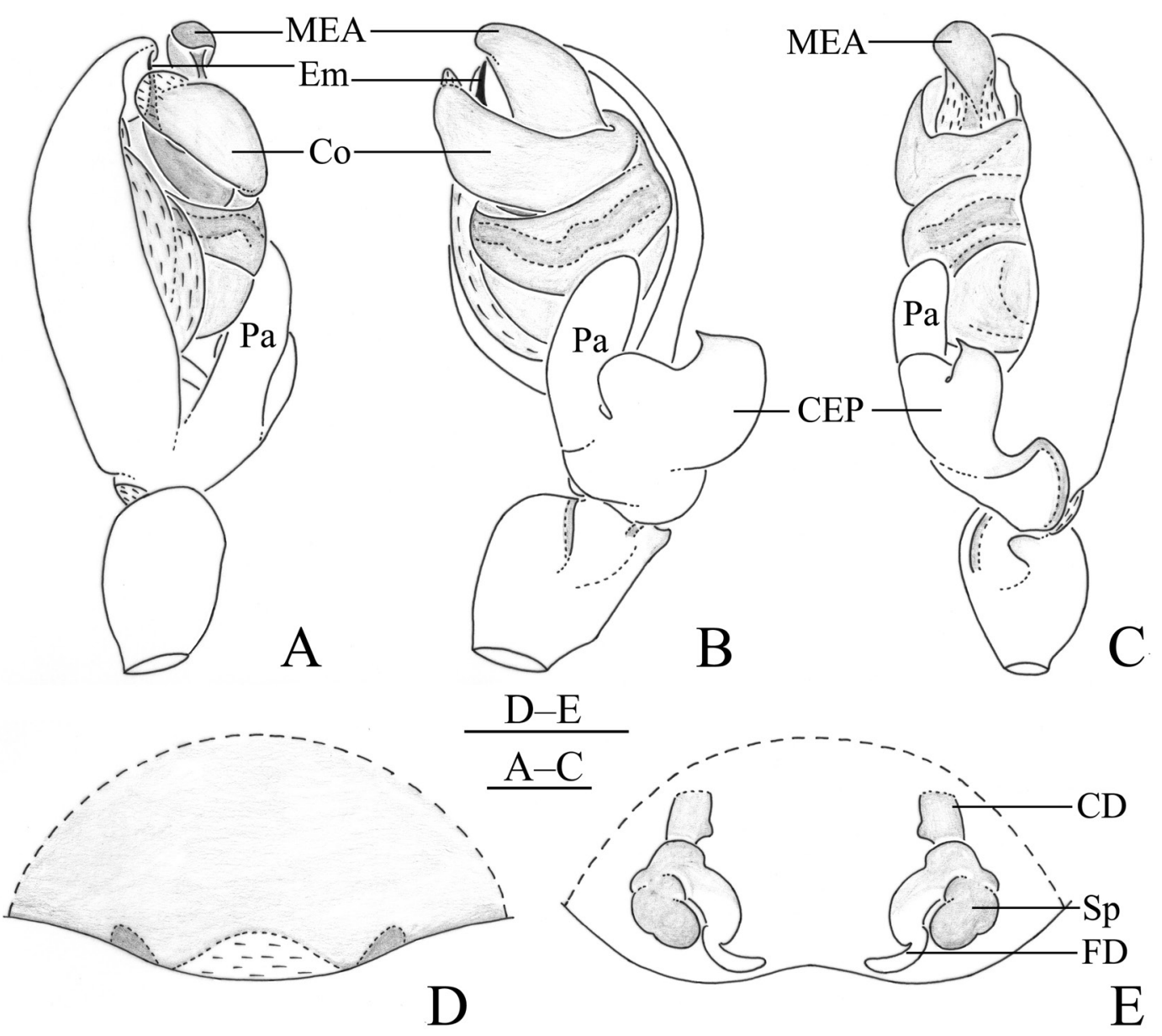

Fig. 15. Meta yinae sp. nov. Left palp of holotype $\widehat{\partial}(\mathrm{A}-\mathrm{C})$; epigyne (D) and vulva (E) of paratype + (HNU-Tang-05-08). A. Prolateral view. B. Ventral view. C. Retrolateral view. D. Epigyne, ventral view. E. Vulva, front view. Scale bars: $0.2 \mathrm{~mm}$. 
Opisthosoma. Oval, dorsum with two pairs of sigillae, yellowish brown, with several irregular black markings (Fig. 1G). Venter of opisthosoma yellowish brown, with black markings.

PalP (Figs 13, 15A-C). Cymbial ectobasal process Y-shaped, with hook-shaped tip. Paracymbium strong and rod-like, with sparse long, brown hairs. Metaine embolic apophysis longer than wide, tongueshaped. Embolus long, thin, proximally covered by conductor. Conductor longer than wide, slightly curved, arising meso-retrolaterally from bulb, extending clockwise, with a membranous end.

Female (HNU-Tang-05-08, Fig. 1H)

MEasurements. Total length 6.17. Prosoma 2.44 long, 2.09 wide; opisthosoma 4.25 long, 3.38 wide. Eye sizes and interdistances: AME 0.15, ALE 0.18, PME 0.17, PLE 0.16; AME-AME 0.09, AME-ALE 0.14, PME-PME 0.10, PME-PLE 0.18, ALE-PLE 0.04. MOA anterior width 0.39, posterior width 0.45, anterior width 0.46 . Clypeus 0.12 high.

LeGs. Leg measurements: I, 11.06 (3.20, 3.86, 2.73, 1.27); II, 8.53 (2.52, 3.01, 2.03, 0.97); III, 5.07 $(1.63,1.68,1.10,0.66)$; IV, $7.18(2.35,2.45,1.65,0.73) . L$ eg formula: 1243 . Other morphological characteristics same as in male.

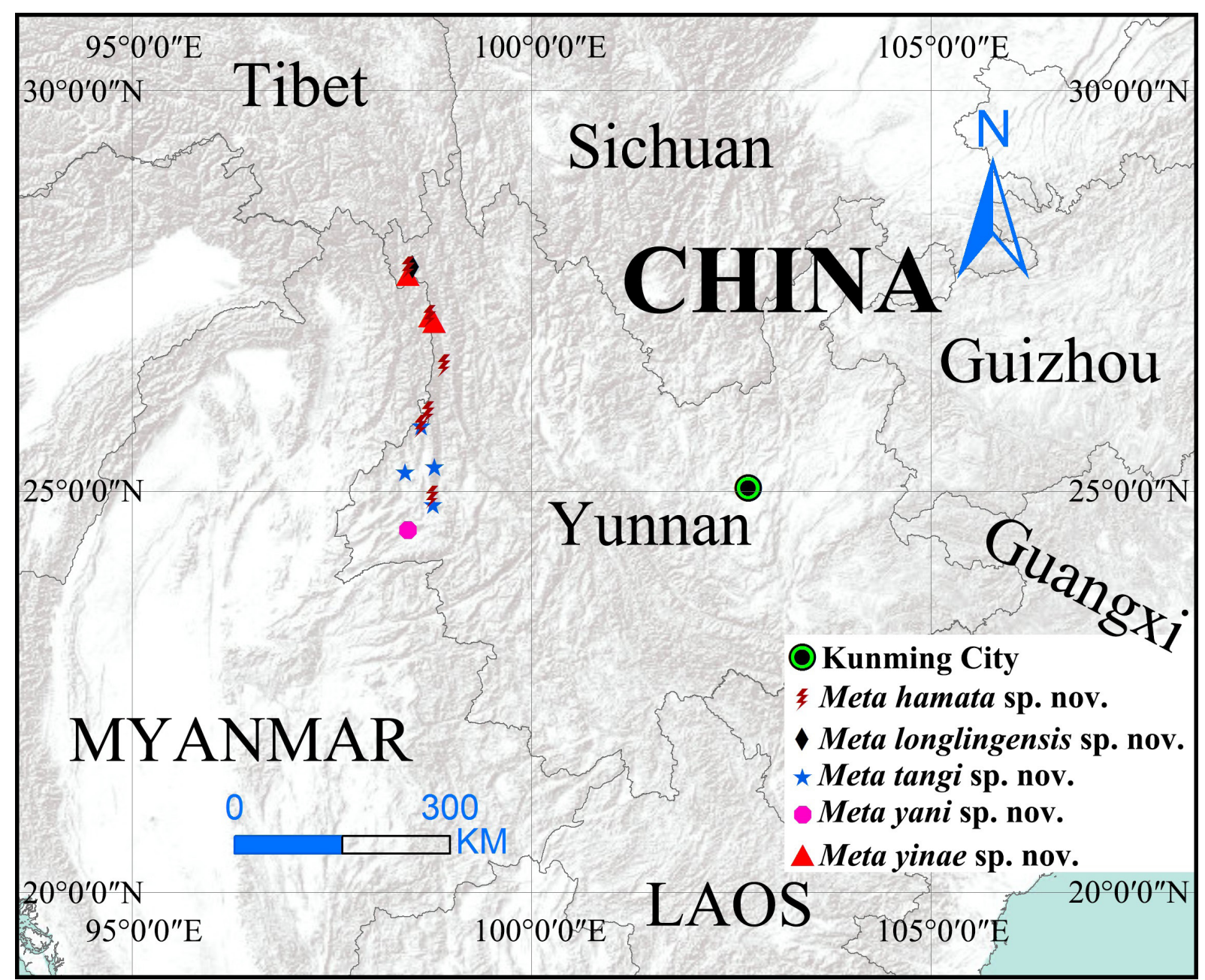

Fig. 16. Distribution records of five new species of the genus Meta Koch, 1836 in Gaoligong Mountains, Yunnan, China. 
Epigyne (Figs 14, 15D-E). Copulatory ducts thick and short. Spermathecae bean-shaped, present posteriorly. Fertilization ducts relatively long and thick.

\section{Variation}

The total length in male specimens examined ranges from 4.79 to 5.29 , in female specimens from 4.95 to 6.74 .

\section{Distribution}

China, Yunnan Province (Fugong, Lushui, Longyang, Tengchong, Gongshan) (Fig. 16).

\section{Discussion}

The genus Meta resembles Metellina Chamberlin \& Ivie, 1941 and Metleucauge Levi, 1980, but can be distinguished by the following characters. Meta fertilization ducts cross over the spermathecae and the metaine embolic apophysis is fused to the embolus base (Álvarez-Padilla \& Hormiga 2011, figs 58c$\mathrm{f}, 60 \mathrm{a}-\mathrm{c})$, whereas Metellina fertilization ducts originate on the anterior surface of the spermathecae (Álvarez-Padilla \& Hormiga 2011, figs 68c, 70d). The Metleucauge epigynum is flat with two deep atria, the male palpal trochanter has a large distal apophysis, and the male palpal femora and tibia are longer than four times its width (Álvarez-Padilla \& Hormiga 2011, fig. 79a, b). The copulatory openings of Meta open posteriorly, apparently the only metaine that does so (Kallal \& Hormiga 2018). The CEP of Meta is wider than in Metellina and has a little spike on the surface. Zhinu has a near-circular gap in the cymbium, the palp is much larger, and the CEP is complex and sclertorized (Kallal \& Hormiga 2018). Moreover, the five new species fit the basic characteristics of Meta.

The members of genus Meta can be found in dark cliffs around cave entrances or among large stones in forest gullies. Due to the specific and isolated habitats of Meta species, the existence of species endemic to individual caves is expected. Continued exploration of the Gongligong Mountains will no doubt lead to the discovery of new species of the long-jawed orbweavers.

\section{Acknowledgements}

We are grateful to Stephanie F. Loria (American Museum of Natural History, New York, USA) for reviewing the English of this manuscript and Mr. Charles Griswold, D.H. Kavanaugh, Xin-ping Wang, Heng-mei Yan, Guo Tang, Peng Hu, Ke-ji Guo, Guang-xu Peng and Zhi-sun Wu for their assistance during the field work and collection. This research was sponsored by the National Special Fund on Basic Research of Science and Technology of China (grant no. 2014FY110100). It was also partly supported by the National Science Foundation of the USA through the "Joint Biodiversity Survey of The SinoAmerican, California Academy of Sciences (CAS)" in the grant "Biotic survey of the Gaoligongshan, a biodiversity hotspot in western Yunnan, China" (grant no. DEB-0103795), National Natural Sciences Foundation of China (NSFC-31702005, 31272271, 31272272, 31301861, 31460476), Hunan Provincial Program for Development of Key Disciplines in Ecology (grant no. 0713).

\section{References}

Álvarez-Padilla F. \& Hormiga G. 2011. Morphological and phylogenetic atlas of the orb-weaving spider family Tetragnathidae (Araneae: Araneoidea). Zoological Journal of the Linnean Society 162: 713-879. https://doi.org/10.1111/j.1096-3642.2011.00692.x

Griswold, C.E., Long, C.L. \& Hormiga, G. 1999. A new spider of the genus Pimoa from Gaoligong Mountains, Yunnan, China (Araneae, Araneoidea, Pimoidae). Acta Botanica Yunnanica, Supplement 11: 91-97. 
Kallal R.J. \& Hormiga G. 2018. An expanded molecular phylogeny of metaine spiders (Araneae, Tetragnathidae) with description of new taxa from Taiwan and the Philippines. Invertebrate Systematics 32 (2): 400-422. https://doi.org/10.1071/IS17058

Li H., Guo H. \& Dao Z. 2000. Flora of Gaoligong Mountains. Science Press, Beijing.

Li S.Q. \& Lin Y.C. 2016. Species Catalogue of China, Vol. 2, Animals, Invertebrates (I), Arachnida: Araneae. Science Press, Beijing.

Miller J.A., Griswold C.E. \& Yin C.M. 2009. The symphytognathoid spiders of the Gaoligongshan, Yunnan, China (Araneae, Araneoidea): Systematics and diversity of micro-orbweavers. ZooKeys 11: 9-195. https://doi.org/10.3897/zookeys.11.160

Myers N., Mittermeier R.A., Mittermeier C.G., Fonseca G.A.B. \& Kent J. 2000. Biodiversity hotspots for conservation priorities. Nature 403: 853-858. https://doi.org/10.1038/35002501

Pickard-Cambridge O. 1885. Araneidea. In: Scientific Results of the Second Yarkand Mission; based upon the Collections and Notes of the Late Ferdinand Stoliczka, Ph. D. Government of India, Calcutta. https://doi.org/10.5962/bhl.title.119960

Schenkel E. 1936. Schwedisch-chinesische wissenschaftliche Expedition nach den nordwestlichen Provinzen Chinas, unter Leitung von Dr Sven Hedin und Prof. Sü Ping-chang. Araneae gesammelt vom schwedischen Artz der Exped. Arkiv för Zoologi 29 (A1): 1-314.

Wan J.L. \& Peng X.J. 2013a. The spiders of the genus Wolongia Zhu, Kim \& Song, 1997 from China (Araneae: Tetragnathidae). Zootaxa 3691: 87-134. https://doi.org/10.11646/zootaxa.3691.1.3

Wan J.L. \& Peng X.J. 2013b. Description of Leucauge tengchongensis sp. nov. and the female of Okileucauge elongatus from Yunnan, China (Araneae: Tetragnathidae). Acta Arachnologica Sinica 22: 16-23. https://doi.org/10.3969/j.issn.1005-9628.2013.01.003 [In Chinese].

Wang X.P., Griswold C.E. \& Ubick D. 2009. On the pseudoterrestris species group of the spider genus Coelotes (Araneae, Amaurobiidae). Zootaxa 2313: 1-34. https://doi.org/10.11646/zootaxa.2313.1.1

Wang X.P., Griswold C.E. \& Miller J.A. 2010. Revision of the genus Draconarius Ovtchinnikov, 1999 (Agelenidae: Coelotinae) in Yunnan, China, with an analysis of the Coelotinae diversity in the Gaoligongshan Mountains. Zootaxa 2593 (1): 1-127. https://doi.org/10.11646/zootaxa.2593.1.1

World Spider Catalog 2020. World Spider Catalog, ver. 21.0. Natural History Museum Bern. Available from http://wsc.nmbe.ch [accessed on 4 Feb. 2020].

Xu X., Yin C.M. \& Griswold C.E. 2002. A new species of the spider genus Macrothele from the Gaoligong Mountains, Yunnan, China (Araneae: Hexathelidae). The Pan-Pacific Entomologist 78: 116-119.

Yin C.M., Griswold C.E. \& Yan H.M. 2002. A new ogre-faced spider (Deinopis) from the Gaoligong Mountains, Yunnan, China (Araneae, Deinopidae). Journal of Arachnology 30: 610-612. Available from https://www.jstor.org/stable/3706074 [accessed 28 Jan. 2020].

Yin C.M., Griswold C.E., Bao Y.H. \& Xu X. 2003a. Four species of the spider genus Steatoda (Araneae: Theridiidae) from the Gaoligong Mountains, Yunnan, China. Proceedings of the California Academy of Sciences 54: 133-140.

Yin C.M., Griswold C.E., Bao Y.H. \& Xu X. 2003b. A new species of the spider genus Craspedisia from the Gaoligong Mountains, Yunnan, China. Bulletin of the British Arachnological Society 12: 383-384. Available from https://eurekamag.com/research/037/658/037658773.php

Yin C.M., Griswold C., Yan H.M. \& Liu P. 2009. Four new species of the spider genus Araneus from Gaoligong Mountains, Yunnan Province, China (Araneae, Araneidae). Acta Arachnologica Sinica 18: $1-10$. 
Manuscript received: 19 July 2019

Manuscript accepted: 4 November 2019

Published on: 8 April 2020

Topic editor: Rudy Jocqué

Desk editor: Marianne Salaün

Printed versions of all papers are also deposited in the libraries of the institutes that are members of the EJT consortium: Muséum national d'histoire naturelle, Paris, France; Botanic Garden Meise, Belgium; Royal Museum for Central Africa, Tervuren, Belgium; Royal Belgian Institute of Natural Sciences, Brussels, Belgium; Natural History Museum of Denmark, Copenhagen, Denmark; Naturalis Biodiversity Center, Leiden, the Netherlands; Museo Nacional de Ciencias Naturales-CSIC, Madrid, Spain; Real Jardín Botánico de Madrid CSIC, Spain; Zoological Research Museum Alexander Koenig, Bonn, Germany; National Museum, Prague, Czech Republic. 